NASA Technical Memorandum 4493

\title{
Actuator and Aerodynamic Modeling for High-Angle-of-Attack Aeroservoelasticity
}

Martin J. Brenner

JUNE 1993

$$
\begin{aligned}
& \text { (NASA-TM-4493) ACTUATOR AND } \\
& \text { AEROOYNAMIC MDOELING FOR } \\
& \text { HIGH-ANGLE-OF-ATTACK } \\
& \text { AEROSERVOFLASTICITY (NASA) } 30 \mathrm{p}
\end{aligned}
$$

N94-13255

Unclas 
NASA Technical Memorandum 4493

\section{Actuator and Aerodynamic Modeling for High-Angle-of-Attack Aeroservoelasticity}

Martin J. Brenner

Dryden Flight Research Facility

Edwards, California

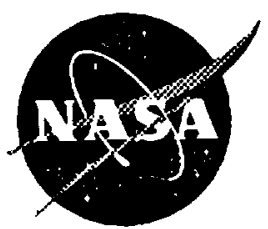

National Aeronautics and

Space Administration

Office of Management

Scientific and Technical Information Program 
1 


\title{
ACTUATOR AND AERODYNAMIC MODELING FOR HIGH-ANGLE-OF-ATTACK AEROSERVOELASTICITY
}

\author{
Martin J. Brenner* \\ NASA Dryden Flight Research Facility \\ P.O. Box 273 \\ Edwards, California 93523-0273
}

\begin{abstract}
Accurate prediction of airframe/actuation coupling is required by the imposing demands of modern flight control systems. In particular, for agility enhancement at high angle of attack and low dynamic pressure, structural integration characteristics such as hinge moments, effective actuator stiffness, and airframe/control surface damping can have a significant effect on stability predictions. Actuator responses are customarily represented with low-order transfer functions matched to actuator test data, and control surface stiffness is often modeled as a linear spring. The inclusion of the physical properties of actuation and its installation on the airframe is therefore addressed in this paper using detailed actuator models which consider the physical, electrical, and mechanical elements of actuation. The aeroservoelastic analysis procedure is described in which the actuators are modeled as detailed high-order transfer functions and as approximate low-order transfer functions. The impacts of unsteady aerodynamic modeling on aeroservoelastic stability are also investigated in this paper by varying the order of approximation, or number of aerodynamic lag states, in the analysis. Test data from a thrust-vectoring configuration of an F/A-18 aircraft are compared to predictions to determine the effects on accuracy as a function of modeling complexity.
\end{abstract}

\section{Nomenclature}

\section{Acronyms}

ASE

GVT

aeroservoelastic
HARV

HOM

LOM

RFCS

TVCS

Symbols

$\mathbf{A}, \mathbf{B}, \mathbf{B}^{\prime}, \mathbf{C}, \mathbf{D}, \mathbf{D}^{\prime}$

$A F 1 B$

$A W F A$

$A W 1 B$

$A_{p}$

a

$b_{\ell}$

"Flight Dynamics Engineer.

Copyright (C)1993 by the American Institute of Aeronautics and Astronautics, Inc. No copyright is asserted in the United States under Title 17, U.S. Code. The U.S. Government has a royalty-free license to exercise all rights under the copyright claimed herein for Governmental purposes. All other rights are reserved by the copyright owner. high-order actuator model

low-order actuator model

research flight control system

thrust vectoring control system
$A W 1 T$

$b_{s}$

$b_{0}, k_{0}, m_{0}$

$b_{1}, k_{1}, m_{1}$

$C_{c}$

$C_{f}$

$C_{p}$

$C_{\mathrm{v}}$

$F_{e}$

aeroservoelastic matrices

antisymmetric fuselage first bending

antisymmetric wing fore-aft

antisymmetric wing first bending

antisymmetric wing first torsion main ram piston area

servovalve port width output structural damping attachment structural damping aerodynamic damping, aerodynamic stiffness, and control surface mass

damping, modal stiffness, and mass

$\frac{n A_{p}^{2}}{k_{T}}+\frac{V_{T}}{4 N}$

general flow coefficient

actuator fluid flow pressure constant

main valve flow coefficient, $=$

$$
C_{f} a \sqrt{\frac{P_{s}-P_{I}}{2}}
$$

externally applied force

ram position feedback gain to servovalve 
$k_{s}$

$m_{p}$

$m_{s}$

$N$

$n$

$P_{j}$

$P_{r}$

$P_{s}$

$P_{1}$

$P_{2}$

$q c$

$S F 1 B$

$S W 1 B$

$S W 1 T$

$s$

$s_{i}$

$V_{T}$

$X$

$\mathbf{x}, \mathbf{y}$

$x_{h}$

$x_{i}$

$x_{\ell}$

$x_{p}$

$x_{s}$

$x_{v}$

$x_{0}$

$x_{1}$

0aero

4aero combined output/attachment structural stiffness,

$$
=\frac{1}{k_{\ell}}+\frac{1}{k_{s}}
$$

output structural stiffness

attachment structural stiffness

mass of main ram piston

mass of main ram body assembly

bulk modulus

number of hydraulic systems operating

pressure difference across piston, $=P_{1}-P_{2}$

return pressure

supply pressure

ram pressure on attachment side

ram pressure on output side

impact pressure boundary

symmetric fuselage first bending

symmetric wing first bending

symmetric wing first torsion

Laplace variable

servoactuator model filter states

total fluid volume in one actuator hydraulic system

nonzero value

state and output vector

actuator ram moment arm

actuator demand from control system

actuator ram displacement

displacement of piston relative to main ram body, $=x_{\ell}-x_{s}$

actuator body displacement

displacement of main control valve

displacement of control surface mass

displacement of structural modal mass

zero-order aerodynamic model

fourth-order aerodynamic model actual control surface rota-

$$
\text { tion, }=-\frac{x_{0}}{x_{h}}
$$

control surface rates

demanded control surface rotation, $=-\frac{x_{i}}{x_{h}}$

displacement and rate, all actuator states

displacement and rate, flexible body states

displacement and rate, rigid body states

servoactuator model filter time constants

actuator stiffness frequency

\section{Introduction}

Agility and performance requirements, as well as a quest for a better understanding of aerodynamics by computational fluid dynamicists, are stimulating the aerospace community to earnestly investigate highangle-of-attack flight. Modern aircraft are being built or reconfigured for enhanced controllability and maneuverability in stalled and poststalled flight regimes. The demanding control tasks at these flight conditions introduce some elements of uncertainty in the modeling of the aircraft dynamics.

Aeroservoelastic (ASE) dynamics include the coupling of structural, control, sensing, aero, and actuator dynamics. Structural dynamics can be accurately, although laboriously, modeled and validated with ground test data. Control dynamics are well understood since they are designed and extensively verified before flying. The primary errors in control feedback sensing come from airdata measurements. Therefore calibration is necessary to quantify the airdata measurement effects on the integrity of the system, and corrections are then made so that the feedbacks also can be reliably modeled. That leaves aerodynamics and actuation as the remaining components of the modeling process.

Standard techniques for computing linear unsteady aerodynamic forces assume potential flow conditions independent of angle of attack. Unsteady measured data are not available and more precise modeling with computational fluid dynamics codes is not feasible for prediction of aeroelastic phenomena at a multitude of flight conditions. Vectoring the engine thrust is a promising technology to compensate for a loss of aerodynamic control power; however, it is accomplished at the expense of becoming another source of model uncertainty by introduction of another coupling 
mechanism. Plume states are difficult to determine for a variety of flight conditions, power levels, and exhaust conditions such as turning vane displacements, nozzle area, and unsteady flow conditions.

At high angle of attack and low dynamic pressure, conventional aerodynamic control surfaces lose their effectiveness and are often driven to their limits. Coupling between the airframe and actuation may become the paramount concern rather than the complex aerodynamics. In particular, structural integration characteristics such as hinge moments, effective actuator stiffness, and airframe/control surface damping become important. Actuators are customarily represented by low-order transfer functions matched to actuator test data, and control surface stiffness is often modeled as a linear spring. ${ }^{1}$ More realistic prediction of airframe/actuation coupling is motivated by the more imposing demands for agility enhancement.

The important ASE modeling uncertainties are, therefore, predominantly a function of aerodynamics and actuation. This paper considers the impact of these modeling uncertainties on predicting ASE dynamics, with emphasis on the high-angle-of-attack flight regime of an F/A-18 aircraft modified with engine exhaust turning vanes for thrust vectoring. As such, detailed actuator models are employed, which consider the physical, electrical, and mechanical elements of actuation. These results are compared with ASE analyses in which the actuators are modeled with low-order transfer functions, and corresponding control surface dynamic stiffness is simulated as a linear spring. Ground test data are used to investigate the differences in accuracy. Since sustained highangle-of-attack flight tends to be limited to low-speed conditions, because of pilot tolerance and for structural integrity reasons, aerodynamic forces are generally low. Hence, if the modal dynamics and the actuation are adequately modeled and validated from ground-testing, it is conceivable that aeroservoelasticity is reduced to essentially a servoelastic phenomenon for this flight regime (unsteady plume aerodynamics are not addressed). This hypothesis is investigated by varying the order of approximation, or number of aerodynamic lag states, in computing the unsteady aerodynamics. Flight test data are used to determine the effects on accuracy as a function of model complexity.

Aeroservoelastic stability analyses have been successfully derived for the X-29A Advanced Technology Demonstrator ${ }^{2,3}$ and the F-15 Short Takeoff and Landing (STOL) Maneuver Technology Demonstrator ${ }^{4}$ at predominantly low angle of attack, but no known published works have addressed the important ASE coupling mechanisms for thrust-vectored configurations and/or high-angle-of-attack flight. This paper describes the ASE modeling procedures and compares simpler low-order models with high-order models of actuators and aerodynamics of an F/A-18 aircraft modified and flight-tested for high-angle-ofattack research. Analysis results are compared with test data and conclusions are drawn as to the accuracy of the various models for high-angle-of-attack flight.

\section{Aircraft Description}

The F/A-18 High Alpha Research Vehicle (HARV) thrust vectoring control system (TVCS) aircraft (Fig. 1(a)) is a modification of a preproduction twin jet engine fighter F-18 aircraft. It was built by the McDonnell Douglas Corp. (St. Louis, Missouri) and the Northrop Corp. (Newbury Park, California). The aircraft has fixed wings without stores, wingtip folds for aircraft carrier storage, wingtip instrumentation pods augmented with airdata sensing devices in place of missile launcher rails, outboard ailerons, inboard trailing-edge flaps, and inboard and outboard leadingedge flaps. All actuators are redundant linear hydromechanical servomechanisms except the leading-edge flap, which is the only rotary mechanical system. The twin vertical tails are angled outward $20^{\circ}$ from the vertical, and horizontal stabilators are attached to the aft fuselage. Leading-edge extensions are attached from the wing root leading edge along the fuselage to the canopy.

An F/A-18 aircraft was modified at the NASA Dryden Flight Research Facility to perform fight research at high angles of attack using thrust vectoring and incorporating control law concepts for agility and performance enhancement, as well as providing data for correlation with computational fluid dynamics solutions. This vehicle is referred to as the HARV TVCS throughout this report. Modifications include the addition of vanes in each engine exhaust for thrust vectoring and corresponding ballast in the forward fuselage to maintain center-of-gravity location; a research flight control system (RFCS) containing the high-angle-ofattack flight research control laws; an inertial navigation system for angle of attack and angle of sideslip rate feedbacks; wingtip angle-of-attack vanes and pressure probes; and additional instrumentation for loads, vane temperatures, and structural dynamics. Hence, the aircraft has significantly different systems and structural characteristics than the basic F/A-18. Aeroservoelastic characteristics were expected to change considerably from the basic F/A-18 because of the reconfiguration.

The TVCS structural modifications include a vectoring system with three engine exhaust vanes radially displaced about each engine axisymmetric nozzle. During activation a vast majority of the time the thrust is directed with two of the three vanes on each engine, while the idle vane is removed from the exhaust plume because of temperature considerations. The horizontal 
stabilator also was modified by trimming 2 percent of the trailing-edge inboard area to provide clearance for the aft end of the outboard TVCS vane fairing assembly.

Total weight added by the aft vane assembly is 2200 $\mathrm{Ib}$, and corresponding ballast in the forward fuselage just in front of the cockpit amounts to $700 \mathrm{lb}$. An additional $1300 \mathrm{lb}$ were added with the installation of the spin chute and subsystem modifications (emergency batteries, modified radome, steel reinforcement, wiring, etc.). The total weight increase from the basic unmodified aircraft is approximately $4200 \mathrm{lb}$. The weight increase resulted in an aft center-of-gravity shift of $4.4 \mathrm{in}$. for the empty aircraft. The internal fuel capacity is $10,620 \mathrm{lb}$ and full takeoff gross weight is approximately $40,000 \mathrm{lb}$.

The F-18 basic control system was modified for the TVCS to permit communication with a RFCS. $^{5}$ To control the vanes, as well as the aerodynamic surfaces, the RFCS is designed to admit feedbacks computed from an inertial navigation system. The research flight envelope (Fig. 1(b)) is restricted to a region bounded by 15,000 to $35,000 \mathrm{ft}$ altitude, and up to a Mach number of 0.7. Beyond an impact pressure of $150 \mathrm{lb} / \mathrm{ft}^{2}$, lateral-directional control is achieved by the basic control laws augmented with an additional yaw vectored thrust command in the rudder command path. The logic to convert a vectored thrust command to six individual vane commands is a very complicated function of estimated gross thrust, throttle position, nozzle position, angle of attack, and altitude, among other parameters. ${ }^{5}$

\section{Aeroservoelastic Modeling Procedure}

\section{Finite-Element Structural Model}

The TVCS modifications such as fairing assemblies, bell cranks, vanes, and hydraulic actuators were incorporated in the basic F/A-18 finite-element model to produce the analysis model shown in Fig. 2(a). The STARS $^{6}$ computer program was used to perform the free vibration analysis for the aircraft configured with full and partial internal fuel with gear up. Frequencies, generalized masses, and mode shapes were then compared with ground vibration test (GVT) results. Table 1 shows good frequency correlation of the symmetric (Table 1(a)) and antisymmetric (Table 1(b)) modes between the GVT and predicted results. Accuracy was essential since these predictions were required in the aeroelastic and ASE analyses. The unique modes of interest for this thrust-vectoring configuration are the vane rotation modes about their respective hinge assemblies. For example, the top vane first rotation mode had a predicted value of $22.10 \mathrm{~Hz}$, which is slightly higher than the measured value of $20.10 \mathrm{~Hz}$.
Hence, test responses exhibited more motion of the vane/actuator fairing attachment point than predicted for the same input force.

A vectored thrust mode shape is generated for each exhaust plume by displacing each of the three vanes according to a specified vectored thrust angle, assuming a constant and equal loading on each vane. The load used was derived from the maximum afterburner thrust estimate, which would be the most common configuration for high angle of attack. The effects of all six vanes are incorporated in this simplified manner to produce a vectored thrust angle, and therefore a control surface mode shape for vectored thrust.

\section{Aerodynamic Model}

Subsonic linear unsteady aerodynamics were calculated using the doublet lattice method. ${ }^{7}$ Figure 2(b) depicts the aerodynamic paneling used in computing the unsteady aerodynamic forces for purely oscillatory motion of each mode over a range of specified reduced frequency values. These generalized aerodynamic forces are tabulated complex values which are valid only for undamped oscillatory motion at low angle of attack. Linear theory may not be applicable at moderate-to-high angle of attack. However, accurate modeling of high-angle-of-attack aerodynamics, whether steady or unsteady, is computationally prohibitive even with a rigid airplane. In fact, precise modeling of vortex dynamics with viscosity and turbulence for an entire aircraft is still a topic of intense research.

Justification for the application of forced oscillation linear theory is based on the following assumptions from Refs. 8 and 9:

- The structural vibrations about a fixed mean angle of attack are relatively small, so the relation between system displacements and motiondependent structural and aerodynamic forces is linear.

- Small-amplitude oscillatory motion has little influence on the unsteady pressures resulting from flow separation.

Also, for full separated flow above $30^{\circ}$ angle of attack, it is assumed that:

- Aerodynamic forces caused by modal vibration do not change appreciably as a function of angle of attack, since the pressures are essentially constant chordwise for a fixed mean angle of attack.

- At low dynamic pressure where sustained highangle-of-attack flight is commonly performed, 
unsteady airloads caused by modal vibration are small and can be reasonably estimated with potential theory.

The generalized aerodynamic forces are extended to the Laplace domain using approximate analytic continuation in order to represent aerodynamic damping. Reference 10 outlines some methods of approximating the generalized force coefficients with matrix formulations of rational functions in $s$, the Laplace variable. These are referred to as Padé approximates in the reduced frequency domain, and are estimates of the time lags associated with unsteadiness in the flow. Subsequently, a linear time invariant state space realization can be formulated for each flight condition.

In this study, the method of least squares detailed in Ref. 3 was used to approximate a Padé partial fraction approximation to the unsteady aerodynamic forces as a function of reduced frequency. The number of partial fractions used to fit the doublet lattice data is the order of the fit. Padé fits to the doublet lattice aerodynamics are designated fourth order for the high-order aerodynamic model. The low-order aerodynamic model applies only zero-order static corrections to the steady aerodynamics. In order to maintain consistency in the calculations, these fits were not optimized using procedures as described in Ref. 10. Low-order models are preferred from a computational point of view because they can be computed much more efficiently and reduce the cost of later ASE analyses. Several stability analyses need to be performed at each flight condition, and the computational cost increases dramatically with the order of the system. Since the actuator models (to be discussed) add a considerable number of states, the lowest order aerodynamic model with adequate accuracy is desired.

Since the low-order model simply represents the unsteady aerodynamics as a residual static correction to the steady aerodynamic data, no aerodynamic states are added and the unsteady dynamics are nullified. Alternatively, the high-order model adds four states for each mode used in the analysis, and it is a precise linear estimate of the unsteady aerodynamics over a broad range of reduced frequency (Ref. 10). Steady aerodynamic data from a linearized version of the full aircraft simulation database are incorporated in the generalized aerodynamic stiffness and damping matrices. ${ }^{3}$ This incorporation thereby imposes the constraint that the aerodynamic forces near zero-reduced frequency match the wind-tunnel-based measured data.

Because of the complexity of the scheduling of individual vane displacements to achieve a command vectored thrust direction (noted previously), the vanes are combined to derive a vectored thrust control mode with respect to a specified thrust level. Vectored thrust force effectiveness is reduced to the steady component of the plume dynamics acting on the vane configuration used to derive the mode shape discussed previously. The orientation of each vane determines the force transmission to the aircraft through the attachment structure. These force effectiveness data were obtained from tests as described in Ref. 11. Unsteady plume effects on the vanes are not modeled.

The assumption is that all the vanes have the same loading as a function of flight condition, on the average. Since the control system attempts to idle one vane in each plume to avoid overheating at all times, the assumption is considered reasonable because at any flight condition each vane will travel between limits of idle and a deflection necessary to achieve a vectored thrust direction. While one vane in each plume is idling, the other two need to compensate to maintain a commanded thrust vector angle. There is no reason to expect that any one vane is a dominant load-carrying member compared to the others during a dynamic maneuver.

\section{Actuator Models}

The validity of an ASE model depends not only on the dynamic modeling of its components but also on the coupling between these components. The airframe, aerodynamics, actuation, and control system must be accurately modeled over a designated frequency range. Actuator responses are customarily represented with transfer functions matched to test results, and control surface stiffness is commonly modeled as a linear spring in the formulation of the airframe dynamics. For highbandwidth flight control systems, as well as agility enhancement at conditions such as high angle of attack, it is preferable to improve the actuation modeling by considering the physical properties of the system and its compliance with the structure. Reference 12 emphasizes, by example, that detailed models based on electrical and hydromechanical elements are desirable for accuracy. In this report the concern is with the sensitivity of actuation coupling mechanisms with the structural dynamics, control dynamics, and aerodynamics.

The F/A-18 control actuation devices are redundant hydromechanical servomechanisms powered by $3000 \mathrm{lb} / \mathrm{in}^{2}$ hydraulic systems. The actuator functional characteristics are shown in Table 2. The aileron actuation operation is used to demonstrate the comprehensive modeling procedure in this paper, which is derived from Ref. 13.

For a linear analysis of the actuation system, the following assumptions are made:

- Linear valve flow

- No valve overlaps, underlaps, or leakage 
- Parallel-sided valve ports

- Equal fluid volumes on each side of the main ram pistons

- Equal areas on each side of the main ram pistons

- No steady load on the ram

- No friction, backlash, or hysteresis

- No limits encountered

Small amplitude characteristics are affected by overlap, hysteresis, friction, and backlash. Limits, port shape, and ram symmetry affect large-amplitude motion. Therefore the model is presumed to be most accurate for medium-range amplitudes.

Linear modeling begins by separating the elements of the actuation system into a plant, which contains mechanical and hydraulic components, and a feedback system which contains servovalve and main ram feedbacks. The diagram in Fig. 3 represents the F/A18 aileron actuator installation and control system. The perturbation of a free control surface couples with the modal dynamics according to the damping $b_{1}$ and modal mass $m_{1}$ of a particular structural mode through the hinge moment. Aerodynamic forces with components of damping $b_{0}$ and stiffness $k_{0}$, furthermore, induce aerodynamic hinge moments. The actuator is attached to the control surface by a lever arm (denoted by damping $b_{\ell}$ and stiffness $k_{\ell}$ ) and to the airframe with some mounting assembly $\left(b_{s}\right.$ and $\left.k_{s}\right)$. The motion of the piston relative to the main ram body, $x_{p}$, is fed back to the commanded signal $x_{i}$. Feedback is also employed in the servovalve.

The servovalve dynamics are assumed to be first order and are combined with an inner loop position feedback. The outer loop ram position feedback controls the ram position according to external demand $x_{i}$ from the control system. Dynamic actuator stiffness is a sum of the airframe attachment stiffness and the control surface lever arm attachment stiffness. Damping comes from these sources as well as structural mode, aerodynamic, and hydraulic origins. External force $F_{e}$ is designated as acting on the main mass from a ground impedance test, for instance, to check stiffness.

Derivation of linear actuation models is valid for multiple hydraulic systems operating the same actuator in tandem or parallel. The systems are assumed identical and the output force produced by the ram is multiplied by $n$ (usually 1 or 2 ), the number of operating systems. For this analysis, output and attachment structural dampings $b_{\ell}$ and $b_{s}$ are assumed zero, and the masses of the main ram body $m_{s}$ and piston $m_{p}$ are neglected. Referring to Fig. 3, in matrix form the main ram hydromechanical dynamic equations become

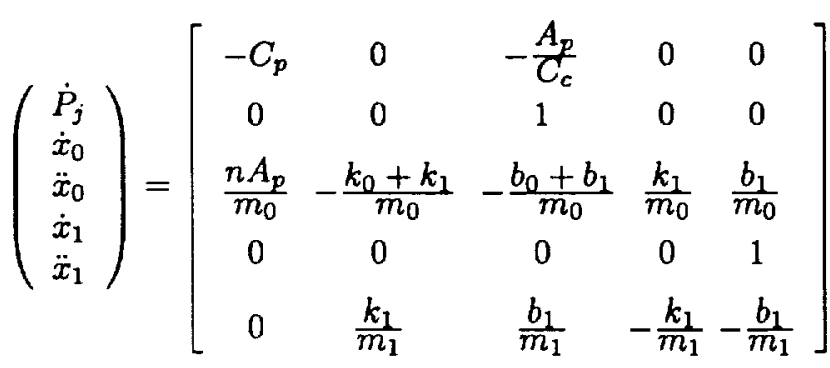

$$
\begin{aligned}
& \left(\begin{array}{c}
P_{j} \\
x_{0} \\
\dot{x}_{0} \\
x_{1} \\
\dot{x}_{1}
\end{array}\right)+\left[\begin{array}{cc}
\frac{C_{u}}{C_{c}} & 0 \\
0 & 0 \\
0 & \frac{1}{m_{0}} \\
0 & 0 \\
0 & 0
\end{array}\right]\left(\begin{array}{c}
x_{v} \\
F_{c}
\end{array}\right) \\
& \left(\begin{array}{l}
x_{p} \\
x_{0}
\end{array}\right)=\left[\begin{array}{ccccc}
\frac{n A_{p}}{k_{T}} & 1 & 0 & 0 & 0 \\
0 & 1 & 0 & 0 & 0
\end{array}\right]\left(\begin{array}{c}
P_{j} \\
x_{0} \\
\dot{x}_{0} \\
x_{1} \\
\dot{x}_{1}
\end{array}\right)
\end{aligned}
$$

for a sign convention assuming that actuator extension always gives negative hinge moment and control rotation. Therefore, for a servovalve command $x_{v}$ or applied test force $F_{e}$, the ram piston is displaced $x_{p}$ relative to the ram body. These equations include the effects of coupling with a structural mode of generalized mass $m_{1}$, and aerodynamic coupling of the surface inertia through the $m_{0}$ terms. The constant $C_{p}$ is a composite coefficient which may be interpreted as a combination of servovalve flow pressure gain and some leakage across the piston head. ${ }^{12}$

By augmenting this main ram model with the servovalve and ram feedbacks shown in Fig. 3, for the F/A-18 aileron actuator ( $s_{i}$ states correspond to respective time constants $\tau_{i}$, and $X$ denotes a nonzero value, which is a function of the system parameters), the equations become:

$\left(\begin{array}{c}\dot{s}_{2} \\ \dot{s}_{1} \\ \dot{s}_{0} \\ \dot{P}_{j} \\ \dot{x}_{0} \\ \ddot{x}_{0} \\ \dot{x}_{1} \\ \ddot{x}_{1} \\ \dot{s}_{3}\end{array}\right)=\left[\begin{array}{ccccc}-\frac{1}{\tau_{2}} & 0 & 0 & 0 & 0 \\ X & -\frac{1}{\tau_{1}} & X & 0 & 0 \\ 0 & 1 & 0 & 0 & 0 \\ 0 & 0 & X & -C_{p} & 0 \\ 0 & 0 & 0 & 0 & 0 \\ 0 & 0 & 0 & \frac{n A_{p}}{m_{0}} & -\frac{k_{0}+k_{1}}{m_{0}} \\ 0 & 0 & 0 & 0 & 0 \\ 0 & 0 & 0 & 0 & \frac{k_{1}}{m_{1}} \\ 0 & 0 & 0 & X & X\end{array}\right.$




$$
\begin{aligned}
& \left.\begin{array}{cccc}
0 & 0 & 0 & X \\
0 & 0 & 0 & 0 \\
0 & 0 & 0 & 0 \\
-\frac{A_{p}}{C_{c}} & 0 & 0 & 0 \\
1 & 0 & 0 & 0 \\
-\frac{b_{0}+b_{1}}{m_{0}} & \frac{k_{1}}{m_{0}} & \frac{b_{1}}{m_{0}} & 0 \\
0 & 0 & 1 & 0 \\
\frac{b_{1}}{m_{1}} & -\frac{k_{1}}{m_{1}} & -\frac{b_{1}}{m_{1}} & 0 \\
0 & 0 & 0 & -\frac{1}{\tau_{3}}
\end{array}\right] \\
& \left(\begin{array}{c}
s_{2} \\
s_{1} \\
s_{0} \\
P_{j} \\
x_{0} \\
\dot{x}_{0} \\
x_{1} \\
\dot{x}_{1} \\
s_{3}
\end{array}\right)+\left[\begin{array}{c}
-x_{h} G_{i} \\
0 \\
0 \\
0 \\
0 \\
0 \\
0 \\
0 \\
0
\end{array}\right] \delta_{d} \\
& \left(\begin{array}{c}
\delta \\
\dot{\delta} \\
x_{p}
\end{array}\right)=\left[\begin{array}{ccccccccc}
0 & 0 & 0 & 0 & -\frac{1}{x_{h}} & 0 & 0 & 0 & 0 \\
0 & 0 & 0 & 0 & 0 & -\frac{1}{x_{h}} & 0 & 0 & 0 \\
0 & 0 & 0 & \frac{n A_{p}}{k_{T}} & 1 & 0 & 0 & 0 &
\end{array}\right] \\
& \left(\begin{array}{c}
s_{2} \\
s_{1} \\
s_{0} \\
P_{j} \\
x_{0} \\
\dot{x}_{0} \\
x_{1} \\
\dot{x}_{1} \\
s_{3}
\end{array}\right)
\end{aligned}
$$

Given the extensive assumptions for linearity and ignoring other system components such as a dynamic leak valve, damper accumulator, or some other pressure feedback modulation, the model is not expected to match measured results exactly. A model for friction would generally add some damping. Also, the fluid coefficients $C_{p}, C_{v}$, and $C_{f}$ are susceptible to error, and the fluid bulk modulus $N$ may differ depending on the type of operating system. ${ }^{12}$ The experience with the F/A-18 actuators was that the servovalve port width a (or equivalently, the main valve flow coefficient $C_{v}$ ), needed to be adjusted to account for variations in valve port shape and size.

Discounting the states resulting from structural and control surface inertias, these high-order actuator models (Table 3) for the F/A-18 HARV TVCS become 7th order for the aileron and turning vanes, 10 th order for the stabilator, 6 th order for the rudder, 7 th order to describe the leading-edge flap, and 8th order for the trailing-edge flap, thereby adding 45 states for each set of symmetric and each set of antisymmetric control modes. The differences in number of states between actuators is predominantly determined by the type of servovalve and the inner loop servovalve feedback mechanism.

Alternatively, low-order models conventionally used for ASE analysis are typically second to fourth order, with a corresponding frequency used to define the dynamic stiffness between the airframe and control surface. They are generated by simply fitting a low-order equivalent transfer function to measured data, with no regard for actuator details. Compliance with the structure is provided by the stiffness frequency, defined as $\omega=\sqrt{k_{T} / m_{0}}$, which is derived from a measured dynamic stiffness $k_{T}$ and surface mass $m_{0}$. The transfer functions and stiffness frequencies used to generate the low-order actuator models in the current study are listed in Table 4 (the leading-edge flap is not shown because of its relative insignificance in control authority). Comparison plots between the analytical highand low-order models, and measured test results, are shown in Fig. 4 for the aileron actuator. This is also representative of the other actuators. Beyond $10 \mathrm{~Hz}$ the test data phase plots show some lag not evident in the analytical results, most likely caused by nonlinearity and the errors in the linear model discussed previously.

\section{State Space Formulation}

Detailed procedures for combining the structural, aerodynamic, and sensor dynamics for an ASE analysis are given in Refs. 3 and 14. The structural model includes rigid body, flexible, and control surface modal dynamics. Cross inertias are also included. In essence, disregarding aerodynamic lag states (for simplicity in demonstration), the state equations take the form

$$
\begin{aligned}
\left(\begin{array}{c}
\dot{\eta}_{r} \\
\dot{\eta}_{e} \\
\ddot{\eta}_{r} \\
\ddot{\eta}_{e}
\end{array}\right) & =[\mathbf{A}]\left(\begin{array}{l}
\eta_{r} \\
\eta_{e} \\
\dot{\eta}_{r} \\
\dot{\eta}_{e}
\end{array}\right)+\left[\begin{array}{ll}
\mathbf{B} & \mathbf{B}^{\prime}
\end{array}\right]\left(\begin{array}{l}
\delta \\
\\
\dot{\delta}
\end{array}\right) \\
\mathbf{y} & =[\mathbf{C}]\left(\begin{array}{c}
\eta_{r} \\
\eta_{e} \\
\dot{\eta}_{r} \\
\dot{\eta}_{e}
\end{array}\right)+\left[\begin{array}{ll}
\mathbf{D} & \mathbf{D}^{\prime}
\end{array}\right]\left(\begin{array}{c}
\delta \\
\\
\dot{\delta}
\end{array}\right)
\end{aligned}
$$

for rigid body states $\eta_{r}$, flexible mode states $\eta_{e}$ (including the structural mode states $x_{1}$ shown previously in the actuator model), control surface displacements $\delta$, and control surface rates $\dot{\delta}$. Actuator states are augmented by adjusting this matrix quadruple as 


$$
\begin{gathered}
\left(\begin{array}{c}
\dot{\eta}_{r} \\
\dot{\eta}_{e} \\
\ddot{\eta}_{r} \\
\ddot{\eta}_{e} \\
\dot{\delta}
\end{array}\right)=\left[\begin{array}{ll}
\mathbf{A} & \mathbf{B} \\
\mathbf{0} & \mathbf{0}
\end{array}\right]\left(\begin{array}{c}
\eta_{r} \\
\eta_{e} \\
\dot{\eta}_{r} \\
\dot{\eta}_{e} \\
\delta
\end{array}\right)+\left[\begin{array}{c}
\mathbf{B}^{\prime} \\
\mathbf{I}
\end{array}\right](\dot{\delta}) \\
\mathbf{y}=\left[\begin{array}{ll}
\mathbf{C} & \mathrm{D}
\end{array}\right]\left(\begin{array}{c}
\eta_{r} \\
\eta_{e} \\
\dot{\eta}_{r} \\
\dot{\eta}_{e} \\
\delta
\end{array}\right)+\left[\mathbf{D}^{\prime}\right](\dot{\delta})
\end{gathered}
$$

The equation for control surface rate $\dot{\delta}$, shown previously, is augmented to this model for each actuator to produce

$$
\begin{aligned}
& \dot{\mathbf{x}}=\overline{\mathbf{A}} \mathbf{x}+\overline{\mathbf{B}} \delta_{d} \\
& \mathbf{y}=\overline{\mathbf{C}} \mathbf{x}+\overline{\mathbf{D}} \delta_{d}
\end{aligned}
$$

where

$$
\mathbf{x}=\left\lceil\eta_{a} \eta_{r} \eta_{e} \dot{\eta}_{r} \dot{\eta}_{e} \delta\right\rfloor
$$

includes all actuator states $\eta_{a}$. This aircraft plant description is augmented with control system dynamics to construct the entire ASE model.

\section{Results and Discussion}

In this section some open-loop comparisons are used to investigate the effects of actuator and aerodynamic modeling. The emphasis here is to determine the sensitivity of the ASE analysis to actuator and aerodynamic model order. Analytical loop gains are determined and compared for the different model complexities. Finally, flight data results are employed to ascertain the relative accuracy of the models in terms of modal stability and frequency-dependent stability margins.

\section{Open-Loop Comparisons}

Data in Fig. 5 compare four pairs of open-loop responses from surface commands to sensor feedbacks between models with high- and low-order actuators, thereby representing a GVT by excluding aerodynamic forces. The comparisons range from being almost identical (pitch thrust vector command to pitch rate) to a different order of magnitude (rudder command to yaw rate), which indicates a lack of consistency in general. Commanded pitch vectored thrust is very insensitive to differences in actuator modeling, yet commanded rudder to feedback responses generally demonstrate significant discrepancy between high- and low-order actuation. An order of magnitude is equivalent to 20 $\mathrm{dB}$, yet the common closed-loop stability criteria for gain stabilization is to attain an 8-dB margin for all structural modes. Therefore a $20-\mathrm{dB}$ open-loop discrepancy may result in erroneous conclusions from a stability analysis. Since the rudder to yaw rate data show the greatest difference between the models of all the responses of Fig. 5, a comparison of the analytical rudder to feedback open-loop responses with GVT data are shown in Fig. 6 . In the rudder command to roll rate response of Fig. 6(a), Fig. 6(b) (rudder command to yaw rate), and Fig. 6(c), (rudder command to lateral acceleration) the high-order model is matching the data better than the low-order model since the loworder model gain tends to be too high. In general, the degree of complexity incorporated in actuator modeling is an important factor in the response characteristics of the dynamic model.

Sensitivity to aerodynamic modeling is shown in the open-loop plots of Fig. 7 , where a flight condition of $30,000-\mathrm{ft}$ altitude, $30 \mathrm{lb} / \mathrm{ft}^{2}$ dynamic pressure, and $40^{\circ}$ angle of attack is used for computing the aerodynamics. Zero-order and fourth-order unsteady aerodynamics are employed in models with low-order actuator dynamics (LOM) in Fig. 7(a), and high-order actuator dynamics (HOM) in Fig. 7(b), using the same four transfer functions of Fig. 5 in each case. Notice that the comparisons are essentially invariant with respect to the order of the aerodynamic fit for each of the four pairs of transfer functions. In fact, at the modal frequencies, the gain values of the modal peaks in Fig. 7, computed with aerodynamics, are very close to the corresponding values in Fig. 5, computed without aerodynamics. This observation lends support to the premise that the aerodynamics, of any order at low dynamic pressure, have an insignificant effect on modal stability. Also, the type of actuator modeling used has little influence on the relative accuracy of the unsteady aerodynamic modeling procedure. Apparently the order of the aerodynamic model does not significantly change the modal response at these fuselage-mounted sensor locations.

However, as indicated in Fig. 8 where the same comparisons are made with aerodynamics computed at another condition of $30,000-\mathrm{ft}$ altitude, $170 \mathrm{lb} / \mathrm{ft}^{2} \mathrm{dy}$ namic pressure, and $5^{\circ}$ angle of attack, there is more distinction between models computed with no aerodynamic lag states and those computed with four lags. These higher dynamic pressure and low-angle-of-attack dissimilarities are seen to be up to 1 or 2 orders of magnitude (pitch thrust vector command to pitch rate in Figs. 8(a) and 8(b)), which is very serious. Therefore, unsteady aerodynamic modeling becomes more important with increasing dynamic pressure. Again, the type of actuator modeling does not affect the character of the comparisons resulting from aerodynamic modeling, as seen by the similar discrepancies between the "4aero" and "0aero" lines in Figs. 8(a) and 8(b). Apparently, actuator/aerodynamic coupling in the form of aerodynamic hinge moments does not vary significantly as a function of actuator model. 


\section{Loop Gain Comparisons}

Gain stabilization criteria specify maximum acceptable loop gains for the model to ensure stability robustness of the actual aircraft dynamics. Sets of analytical single-input-single-output longitudinal, lateral, and directional loop gains are shown in Figs. 9(a) through 9 (d) for flight conditions at $5^{\circ}, 10^{\circ}, 40^{\circ}$, and $70^{\circ}$ angle of attack, respectively. Dissimilarities between the models incorporating low- and high-order actuator dynamics are apparent at all conditions. At the lowangle-of-attack and higher dynamic pressure conditions of Fig. 9(a) (170 lb/ $\mathrm{ft}^{2}$ dynamic pressure $)$ and to a lesser extent Fig. 9(b) (100 lb/ $\mathrm{ft}^{2}$ dynamic pressure), the impact of aerodynamic and actuator modeling is distinct especially in the directional axis. The large miscomparisons in the directional axis stem from differences in dynamics seen in the rudder to yaw rate responses of Fig. 5 (actuator models), and Figs. 8(a) and 8 (b) (aerodynamic models), in addition to other lateral-directional feedback responses that were not shown. In fact, in the directional axis at $5^{\circ}$ angle of attack, a change in gain of nearly $20 \mathrm{~dB}$ appears to be caused independently by actuator modeling and aerodynamic modeling, thereby summing to a total of approximately $40 \mathrm{~dB}$. In Fig. 9 (c) $\left(40^{\circ}\right.$ angle of attack) and Fig. $9(\mathrm{~d})\left(70^{\circ}\right.$ angle of attack), the responses are from conditions at the same low dynamic pressure of $30 \mathrm{lb} / \mathrm{ft}^{2}$. The only source for differences between the plots in Fig. 9(c) compared to Fig. 9(d) is in the control laws. The only cause of discrepancy with in each plot is in the actuator modeling. The low-order actuator models seem to exhibit more of a tendency toward instability with either aerodynamic model, as evidenced by the highest loop gains.

In the low dynamic pressure and high-angle-of-attack conditions of Figs. 9(c) and 9(d), the loop gains show that differences resulting from aerodynamic modeling are clearly negligible compared to the clear distinctions resulting from actuator modeling. The loop gains computed from the low-order actuator models generally give much more conservative stability predictions, which could result in needless system modifications for safety of flight.

\section{Damping Comparisons With Flight Data Results}

Modal frequency and damping estimated from flight test data are compared with analytical results in Fig. 10 for the same flight conditions as Fig. 9. The symmetric wing torsion mode near $11 \mathrm{~Hz}$ was consistently predicted to be at a slightly higher frequency of $12 \mathrm{~Hz}$. In general, the predicted symmetric modal dampings and most antisymmetric modal dampings seem to agree favorably with the flight-derived results, and the damping values are not very sensitive to varia- tions in the models. However, there are some noteworthy exceptions.

At the $5^{\circ}$ angle-of-attack condition (Fig. 10(a)), the low-order actuator result with four aerodynamic lag terms yields a damping level that is too conservative (unstable) near $9 \mathrm{~Hz}$ (antisymmetric wing first bending), yet the same actuator modeling with no aerodynamic lag terms gives a modal damping near $9 \mathrm{~Hz}$, which is too high. This extreme variability between high- and low-order aerodynamic modeling with loworder actuator modeling at low angle of attack and high dynamic pressure was also indicated in the directional loop gain of Fig. 9(a).

Another anomaly occurs at the $70^{\circ}$ angle-of-attack condition in Fig. 10(d), where the low-order actuator modeling produces damping levels that are too high compared with the flight estimates near $9 \mathrm{~Hz}$ (antisymmetric wing first bending) and $13 \mathrm{~Hz}$ (antisymmetric wing first torsion), even though Fig. 9(d) indicated loop gains greater than $0 \mathrm{~dB}$ at these frequencies. It seems that combining low-order actuator models with either aerodynamic model is producing more phase-sensitive predictions since gain stabilization criteria are not met even though damping is more than adequate. Loworder actuator models only account for very simplistic coupling between the airframe and actuators, so it is expected that the predicted phase is inaccurate at the modal frequencies. In addition, the predicted closedloop damping levels are not robust using low-order actuator models.

Open-loop responses from actuator commands to feedback sensors, with no aerodynamics modeled, clearly show that actuator modeling may have serious consequences for model accuracy. When unsteady aerodynamic accuracy is varied from zero order to fourth order, ASE response may change appreciably in higher dynamic pressure regimes, yet negligibly in high-angle-of-attack flight at low dynamic pressure. Hence, unsteady aerodynamic modeling has a negligible effect on ASE stability at high angle of attack and low dynamic pressure, whereas actuator modeling can be consequential at any flight condition. Low-order actuator models indicate a tendency toward unreliable behavior when augmented with various unsteady aerodynamic models.

\section{Concluding Remarks}

The consequences of aerodynamic and actuator modeling on aeroservoelasticity, with emphasis on highangle-of-attack flight, were investigated to reveal the important aspects for stability predictions. Aeroservoelastic (ASE) analyses were performed in which the actuators are modeled as detailed high-order transfer functions and as approximate low-order transfer 
functions. The impacts of the unsteady aerodynamic modeling were examined by varying the order of approximation, or number of aerodynamic lag states, in the formulation. Test data from a thrust-vectoring configuration of an F/A-18 aircraft are compared to predictions to determine the effects on accuracy as a function of modeling complexity.

High-angle-of-attack ASE analyses require detailed actuator dynamics modeling. Detailed modeling of actuator hydraulic and electromechanical properties is important for any ASE analysis regardless of flight condition. However, the coupling mechanisms between actuation and structural dynamics are more pronounced with the decreased dynamic pressure characteristic of sustained high-angle-of-attack flight. Unsteady aerodynamic forces are relatively insignificant for modal stability analyses at these flight conditions. Closedloop stability predictions compared with flight-derived estimates show that a low-order actuator model may produce unreliable stability estimates at any flight condition.

\section{References}

${ }^{1}$ Zimmermann, Helmut, "Aeroservoelasticity," Computer Methods in Applied Mechanics and Engineering, vol. 90, 1991, pp. 719-735.

${ }^{2}$ Zislin, A., E. Laurie, K. Wilkinson, and R. Goldstein, "X-29 Aeroservoelastic Analysis and Ground Test Validation Procedures," AIAA-85-3091, Oct. 1985.

${ }^{3}$ Gupta, K.K., M.J. Brenner, and L.S. Voelker, Development of an Integrated Aeroservoelastic Analysis Program and Correlation with Test Data, NASA TP3120, 1991.

${ }^{4}$ Cheng, Peter Y., R.C. Jones, and S.M. Murnyack, "STOL Maneuver Technology Demonstrator Aeroservoelasticity," AIAA-90-3336, Aug. 1990.

${ }^{5}$ Pahle, Joseph W., Bruce Powers, Victoria Regenie, Vince Chacon, Steve Degroote, and Steven Murnyak, Research Flight-Control System Development for the
F-18 High Alpha Research Vehicle, NASA TM-104232, 1991.

${ }^{6}$ Gupta, K.K., STARS-An Integrated GeneralPurpose Finite Element Structural, Aeroelastic, and Aeroservoelastic Analysis Computer Program, NASA TM-101709, 1990. Also revised 1991.

${ }^{7}$ Taylor, R.F., K.L. Miller, and R.A. Brockman, "A Procedure for Flutter Analysis of FASTOP-3 Compatible Mathematical Models, Vol. 1 - Theory and Application," AFWAL-TR-81-3036, June 1981.

${ }^{8}$ Bublitz, P. and H. Zingel, "Experimental Investigations of Buffet Excitation Forces on a Low Aspect Ratio Trapezoidal Half Wing in Incompressible Flow," Aircraft Dynamic Loads due to Flow Separation, AGARDCP-483, 1990, pp. 5-1-5-19.

${ }^{9}$ Försching, H.W., "Unsteady Aerodynamic Forces on an Oscillating Wing at High Incidences and Flow Separation," Aircraft Dynamic Loads due to Flow Separation, AGARD-CP-483, 1990, pp. 7-1-7-18.

${ }^{10}$ Tiffany, Sherwood H. and William M. Adams, Jr., Nonlinear Programming Extensions to Rational Function Approximation Methods for Unsteady Aerodynamic Forces, NASA TP-2776, 1988.

${ }^{11}$ Bowers, Albion H., Gregory K. Noffz, Sue B. Grafton, Mary L. Mason, and Lee R. Peron, Multiaxis Thrust Vectoring Using Axisymmetric Nozzles and Postexit Vanes on an F/A-18 Configuration Vehicle, NASA TM-101741, 1991.

${ }^{12}$ Edwards, John W., Analysis of an Electrohydraulic Aircraft Control-Surface Servo and Comparisons with Test Results, NASA TN D-6928, 1972.

${ }^{13}$ Stirling, R., "Linearized Model of the Jaguar Flyby-Wire Actuation System," University of Bristol, Department of Aeronautical Engineering, Report no. RS/2/83, Oct. 1983.

${ }^{14}$ Stirling, R., "Flexible Aircraft and Control System Dynamics," University of Bristol, Department of Aeronautical Engineering, Report no. RS/3/84, July 1984. 
Table 1. Free vibration analysis results for the F/A-18 HARV.

(a) Symmetric modes.

\begin{tabular}{|c|c|c|c|c|}
\hline \multirow[b]{2}{*}{ Primary motion } & \multicolumn{2}{|c|}{ Light weight (2500 lb fuel) } & \multicolumn{2}{|c|}{ Heavy weight (full fuel) } \\
\hline & $\begin{array}{c}\text { Predicted } \\
\text { frequency, } \mathrm{Hz}\end{array}$ & $\begin{array}{c}\text { GVT } \\
\text { frequency, } \mathrm{Hz}\end{array}$ & $\begin{array}{c}\text { Predicted } \\
\text { frequency, } \mathrm{Hz}\end{array}$ & $\begin{array}{c}\text { GVT } \\
\text { frequency, } \mathrm{Hz}\end{array}$ \\
\hline Wing first bending & 5.83 & 6.08 & 5.75 & 6.02 \\
\hline Fuselage first bending & 7.97 & 8.19 & 7.45 & 7.76 \\
\hline Wing first torsion & 11.71 & 11.78 & 11.64 & 11.80 \\
\hline Stabilator first bending & 13.77 & 13.78 & 13.68 & 13.63 \\
\hline Fin first bending & 15.92 & 15.72 & 15.92 & 15.68 \\
\hline Fuselage second bending & 16.39 & 16.20 & 15.34 & 15.23 \\
\hline Wing second bending & 18.05 & -- & 17.05 & 17.01 \\
\hline Wing fore-aft & 18.86 & --- & 18.19 & --- \\
\hline Vane rotation & 22.10 & 20.10 & 22.10 & 20.10 \\
\hline Inboard flap rotation & 23.70 & --- & 23.50 & -- \\
\hline Wingtip torsion & 27.52 & --- & 27.47 & --- \\
\hline
\end{tabular}

(b) Antisymmetric modes.

\begin{tabular}{lccrcc}
\hline \hline & \multicolumn{2}{c}{ Light weight (2500 lb fuel) } & & \multicolumn{2}{c}{ Heavy weight (full fuel) } \\
\cline { 2 - 3 } \cline { 5 - 6 } Primary motion & $\begin{array}{c}\text { Predicted } \\
\text { frequency, Hz }\end{array}$ & $\begin{array}{c}\text { GVT } \\
\text { frequency, Hz }\end{array}$ & & $\begin{array}{c}\text { Predicted } \\
\text { frequency, } \mathrm{Hz}\end{array}$ & $\begin{array}{c}\text { GVT } \\
\text { frequency, Hz }\end{array}$ \\
\hline Fuselage first bending & 7.40 & 7.25 & & 6.86 & 6.64 \\
Wing first bending & 8.88 & 8.48 & & 8.61 & 8.33 \\
Wing first torsion & 12.03 & 12.20 & & 12.02 & 12.13 \\
Stabilator first bending & 13.69 & 13.58 & & 13.57 & 13.45 \\
Wing fore-aft & 15.36 & 15.25 & & 14.99 & 15.09 \\
Fin first bending & 15.85 & --- & & 15.56 & 15.31 \\
Fuselage first torsion & 19.50 & --- & & 18.76 & 22.00 \\
Fuselage second bending & 21.83 & --- & & 21.01 & --- \\
Vane rotation & 22.10 & 20.10 & & 22.10 & 20.10 \\
Inboard flap rotation & 23.33 & --- & & 23.02 & --- \\
Fore-fuselage torsion & 24.36 & --- & & 23.98 & --- \\
\hline
\end{tabular}


Table 2. F/A-18 HARV actuation system functional characteristics.

\begin{tabular}{|c|c|c|c|c|}
\hline & $\begin{array}{c}\text { Vanes } \\
\text { and } \\
\text { aileron }\end{array}$ & Rudder & Stabilator & $\begin{array}{c}\text { Trailing-edge } \\
\text { flap }\end{array}$ \\
\hline \multicolumn{5}{|l|}{ Output force, $\mathrm{lb}$} \\
\hline Surface extended & 13,100 & 15,740 & 29,940 & 18,070 \\
\hline Surface retracted & 12,090 & 13,880 & 27,250 & 14,330 \\
\hline Surface deflection, deg & 70.0 & 60.0 & 34.5 & 53.0 \\
\hline \multicolumn{5}{|l|}{ Piston area, $\mathrm{in}^{2}$} \\
\hline Surface extended & 4.71 & 5.64 & 10.50 & 6.16 \\
\hline Surface retracted & 4.40 & 5.07 & 9.72 & 4.95 \\
\hline Stroke, in. & 4.38 & 1.43 & 7.12 & 8.12 \\
\hline \multicolumn{5}{|l|}{ Maximum horn arm, in. } \\
\hline Aileron only & 4.0 & 1.43 & 12.0 & 9.08 \\
\hline Vane only & 9.2 & --- & --- & --- \\
\hline Output velocity, in/sec & 6.70 & 1.33 & 7.40 & 2.76 \\
\hline Surface rate, $\mathrm{deg} / \mathrm{sec}$ & 100.0 & 56.0 & 40.0 & 18.0 \\
\hline Loop gain, $\mathrm{sec}^{-1}$ & 48 & 37 & 30 & 18 \\
\hline Dynamic stiffness, lb/in. $\times 10^{-5}$ & 2.7 & 6.0 & 2.0 & 0.9 \\
\hline Maximum free play, deg & 0.126 & 0.573 & 0.10 & 0.573 \\
\hline Hydraulic flow, gal/min & 8.1 & 2.1 & 19.8 & 4.4 \\
\hline
\end{tabular}

Table 3. High-order actuator model data.

\begin{tabular}{|c|c|}
\hline Control surface & Transfer function \\
\hline $\begin{array}{l}\text { Trailing-edge } \\
\text { flaps }\end{array}$ & $\left(1.5 \times 10^{14}\right) \frac{(s+284)(s+808)}{(s+15.4)(s+76.2)(s+469)(s+1033)\left[s^{2}+2(.98)(304) s+304^{2}\right)\left[s^{2}+2(.011)(817) s+817^{2}\right]}$ \\
\hline Ailerons & $\left(2.0 \times 10^{16}\right)_{\left[s^{2}+2(.62)(69.1) s+69.1^{2}\right]\left[s^{2}+2(.94)(392) s+392^{2}\right]\left[s^{2}+2(.82)(746) s+746^{2}\right](s+17326)}^{(s+356)}$ \\
\hline Stabilators & $\left(3 \times 10^{14}\right) \frac{(s+284)(s+808)\left[s^{2}+2(.07)(72) s+72^{2}\right]}{(s+384)(s+1098)\left[s^{2}+2(.6)(30) s+30^{2}\right)\left[s^{2}+2(.8)(127) s+127^{2}\right)\left(s^{2}+2(.9)(335) s+335^{2}\right]\left[s^{2}+2(.02)(718) s+718\right]}$ \\
\hline Rudders & $\left(2.6 \times 10^{13}\right) \frac{(s+357)}{\left.(s+14.4)(s+224)(s+431)(s+607) s^{2}+2(.006)(3335) s+3335^{2}\right)}$ \\
\hline Vanes & $\left(1.6 \times 10^{15}\right) \frac{(s+356)}{(s+725)\left[s^{2}+2(.79)(75) s+75^{2}\right]\left[s^{2}+2(.79)(475) s+475^{2}\right]\left[s^{2}+2(.82)(781) s+781^{2}\right]}$ \\
\hline
\end{tabular}

Table 4. Low-order actuator model data.

\begin{tabular}{lcc}
\hline Control surface & \multicolumn{1}{c}{ Transfer function } & Stiffness frequency, $\mathrm{Hz}$ \\
\hline Trailing-edge flaps & $\frac{35^{2}}{s^{2}+2(0.71)(35) s+35^{2}}$ & 4 \\
Ailerons & $\frac{75^{2}}{s^{2}+2(0.59)(75) s+75^{2}}$ & 16 \\
Stabilators & $\frac{30.8^{2}}{s^{2}+2(0.51)(30.8) s+30.8^{2}}$ & 2.4 \\
Rudders & $\frac{72^{2}}{s^{2}+2(0.69)(72) s+72^{2}}$ & 44 \\
Vanes & $\frac{75^{2}}{s^{2}+2(0.59)(75) s+75^{2}}$ & 8 \\
\hline \hline
\end{tabular}




$$
\begin{aligned}
& \text { ORIIINAL PACIE }
\end{aligned}
$$

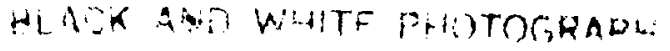

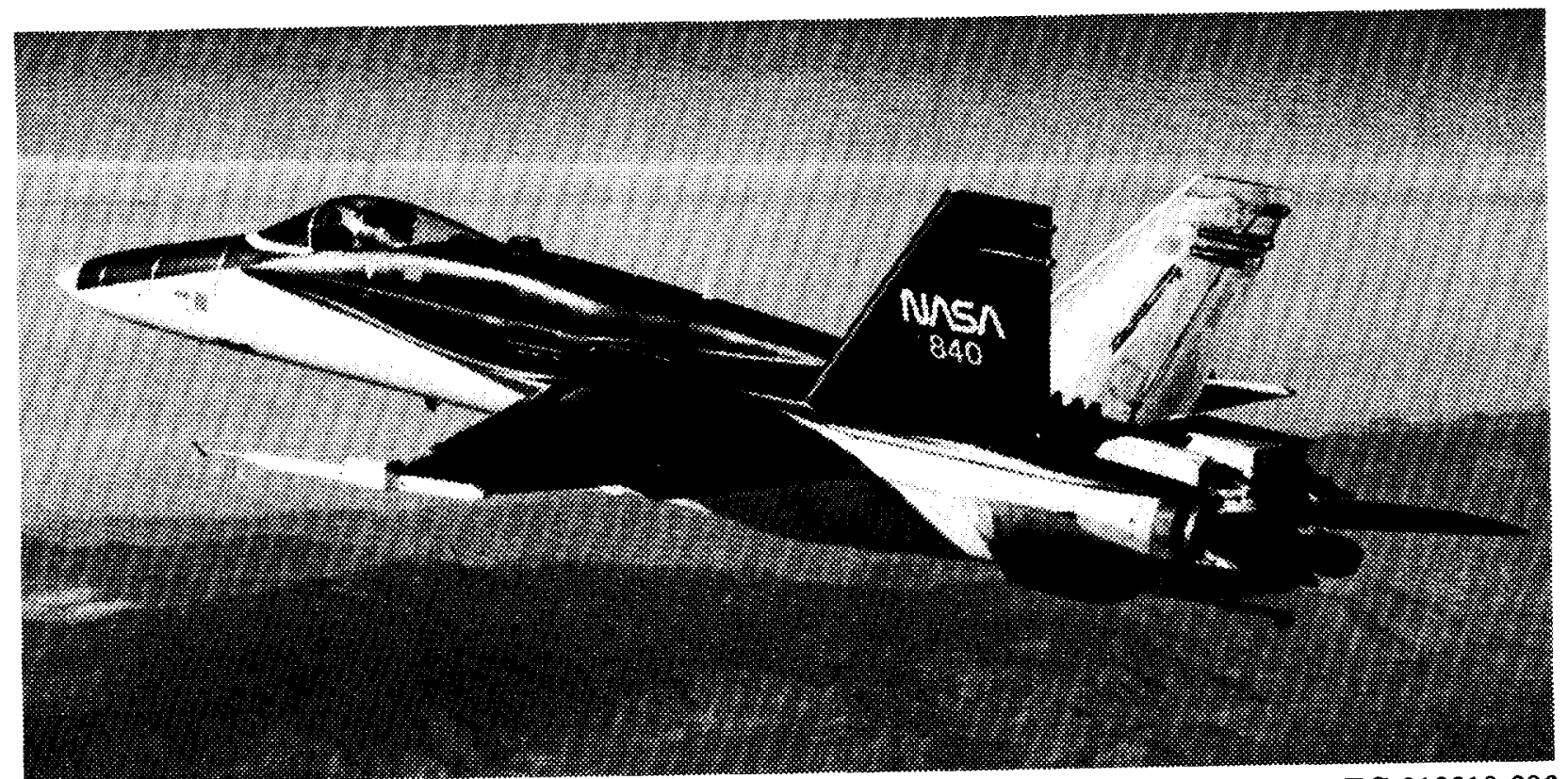

EC 910010-006

(a) F/A-18 HARV in flight with the TVCS installed.

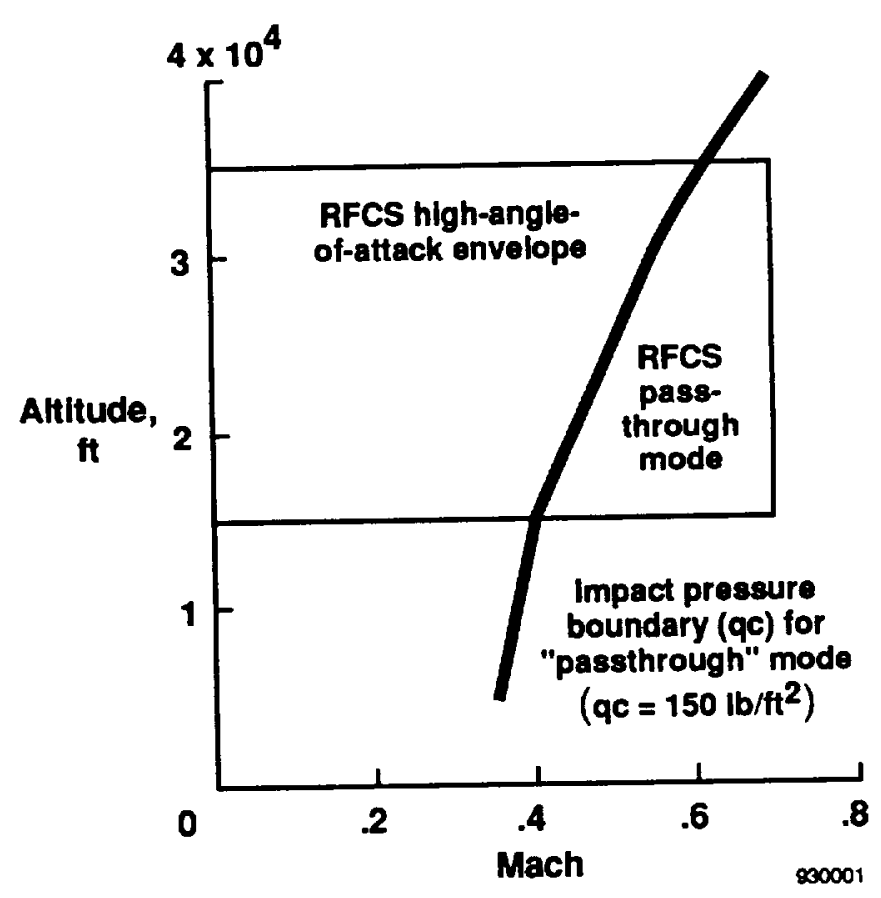

(b) RFCS flight envelope.

Fig. 1 F/A-18 HARV TVCS and RFCS flight envelope. 


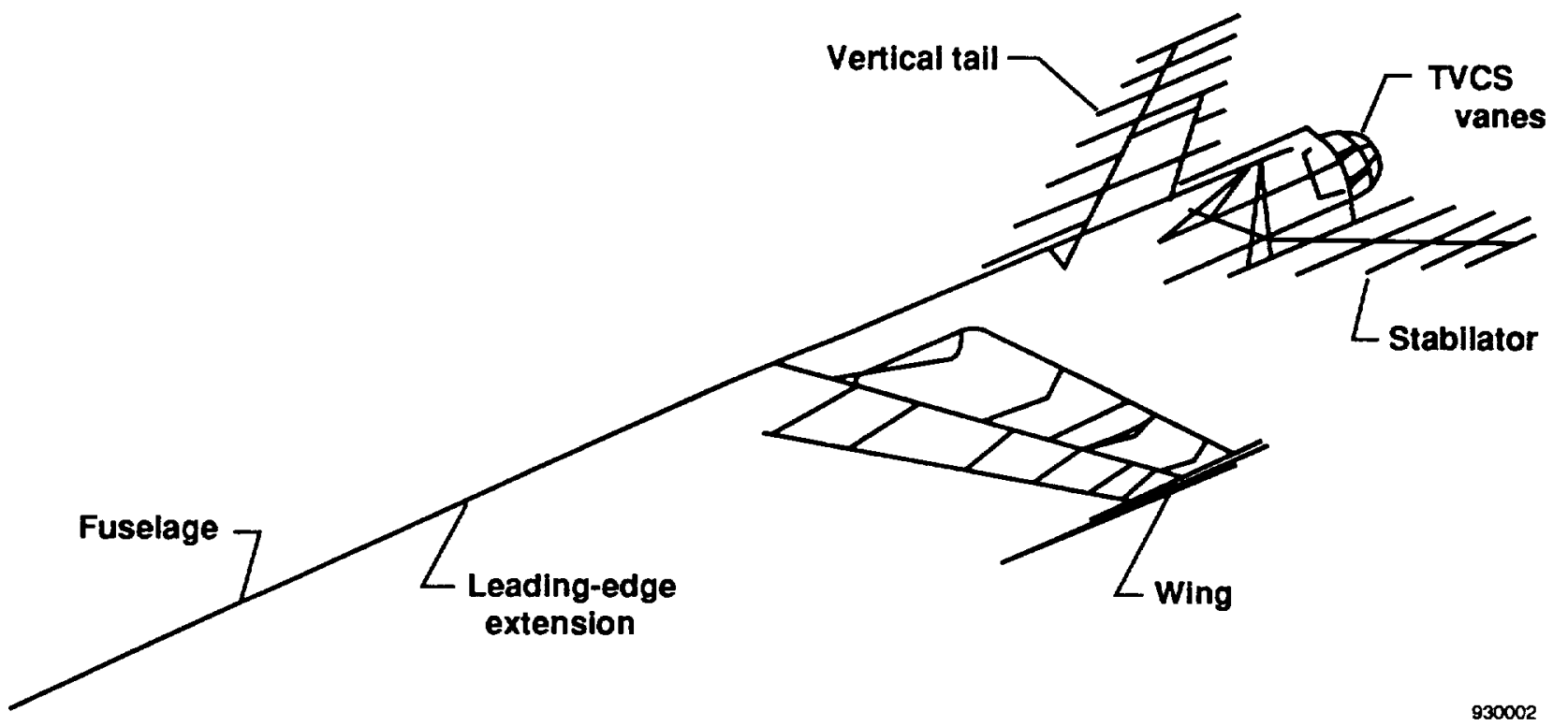

(a) F/A-18 HARV TVCS finite-element model.

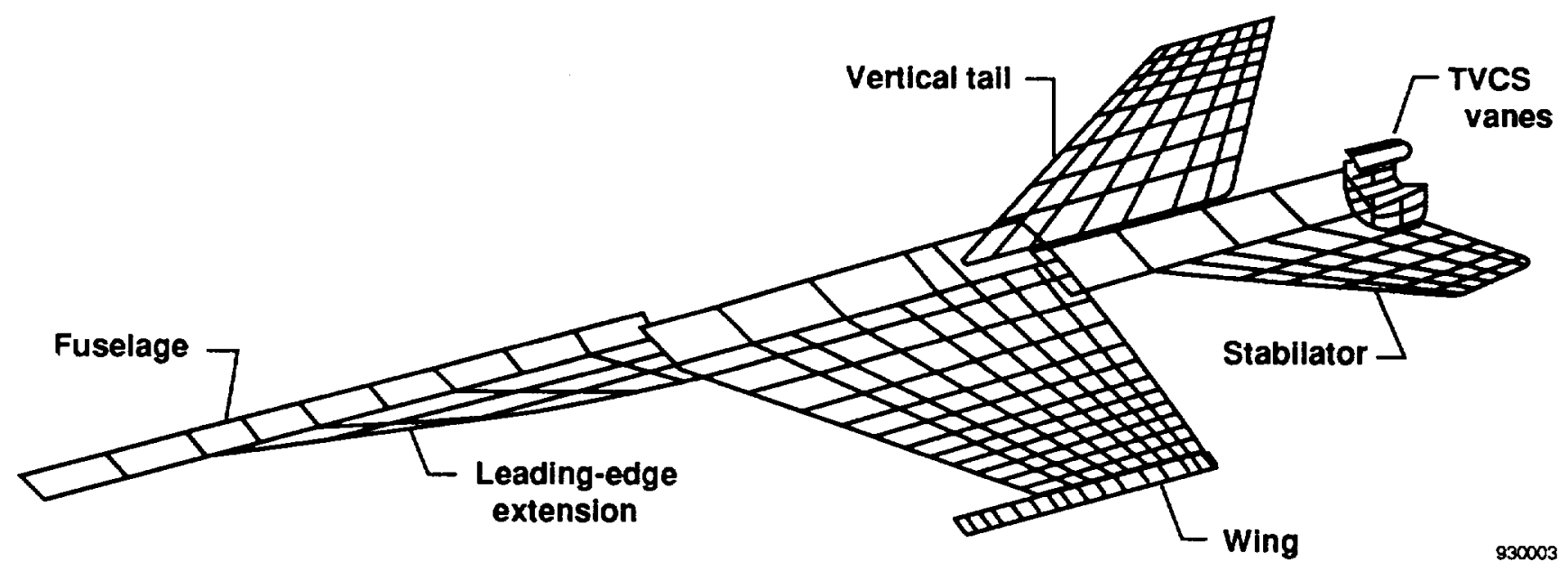

(b) F/A-18 HARV TVCS unsteady aerodynamic model.

Fig. 2 F/A-18 HARV TVCS finite-element and unsteady aerodynamic models. 


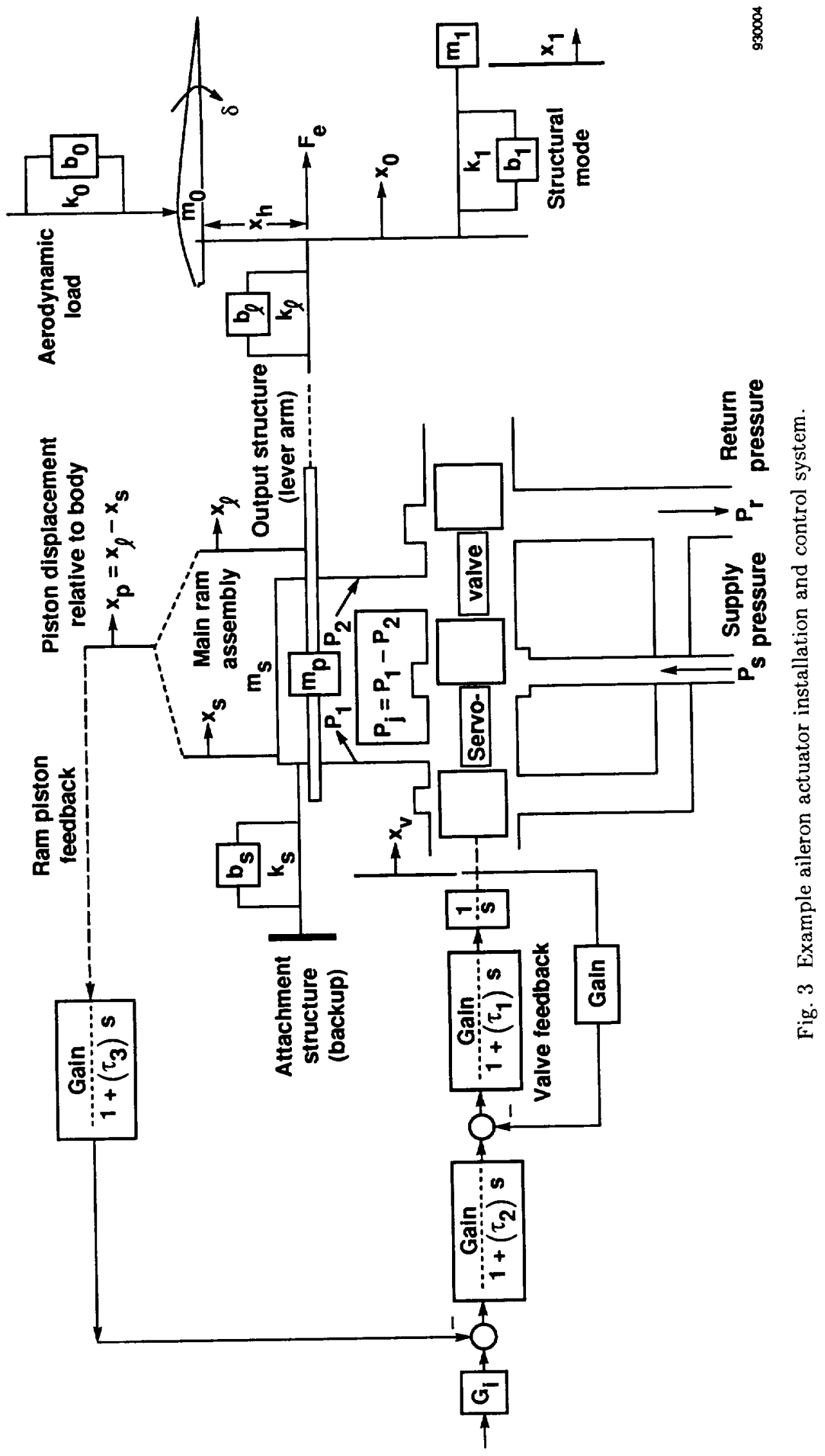



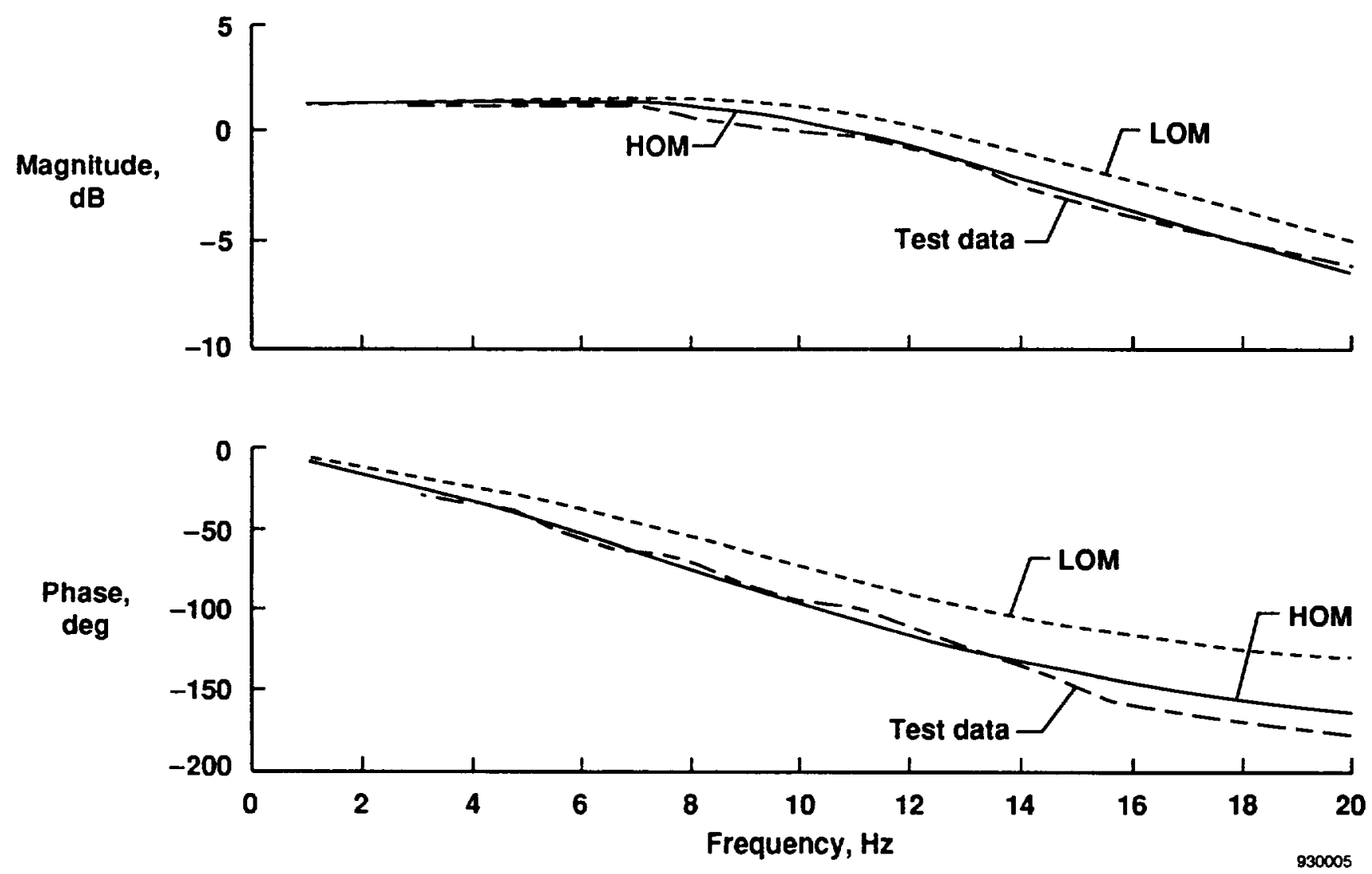

Fig. 4 Frequency response of aileron actuator high- and low-order analytical models compared with test data. 

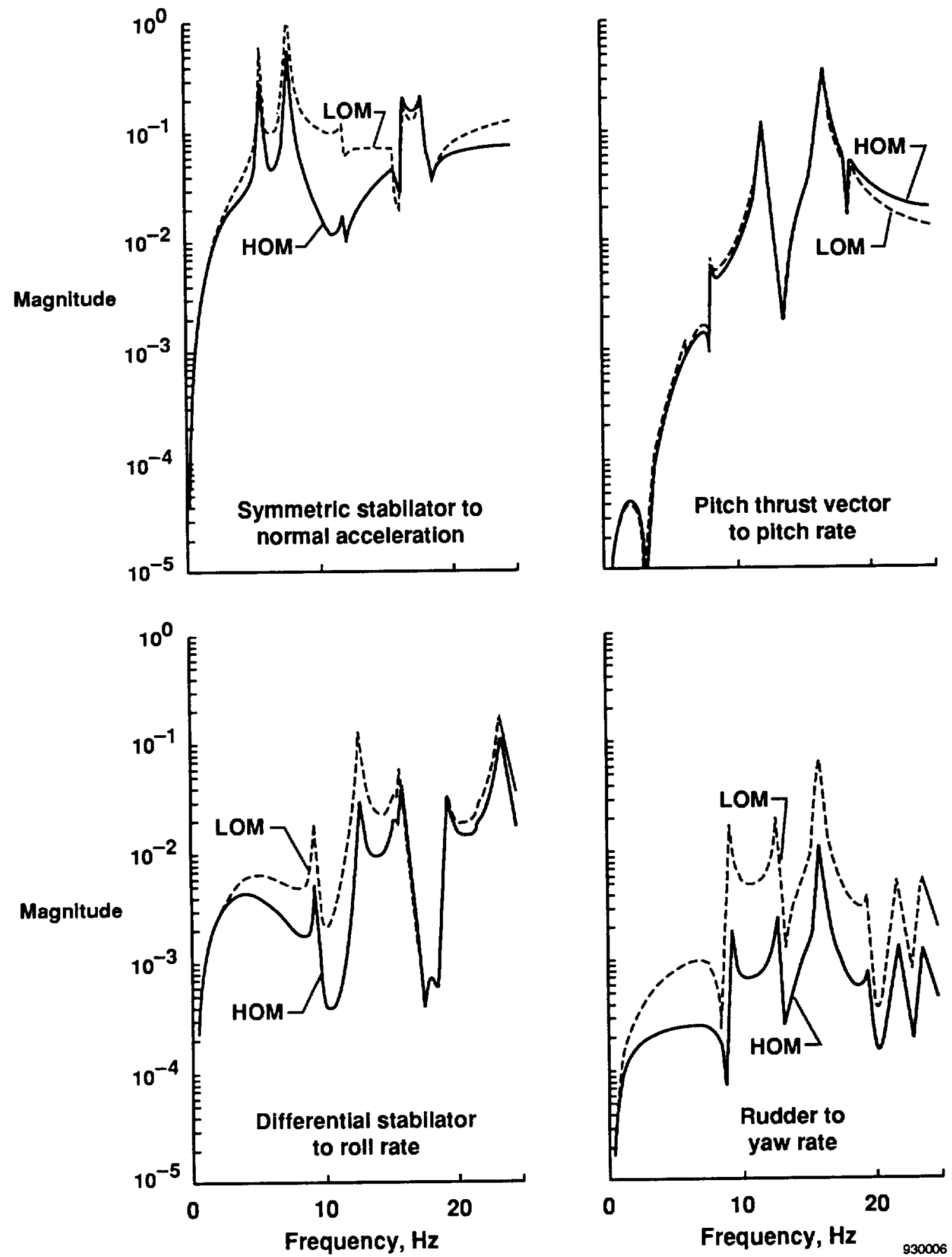

Fig. 5 Open-loop frequency response comparisons of surface command to sensor feedback between servoelastic models with high-order model (HOM) and low-order model (LOM) actuators. 


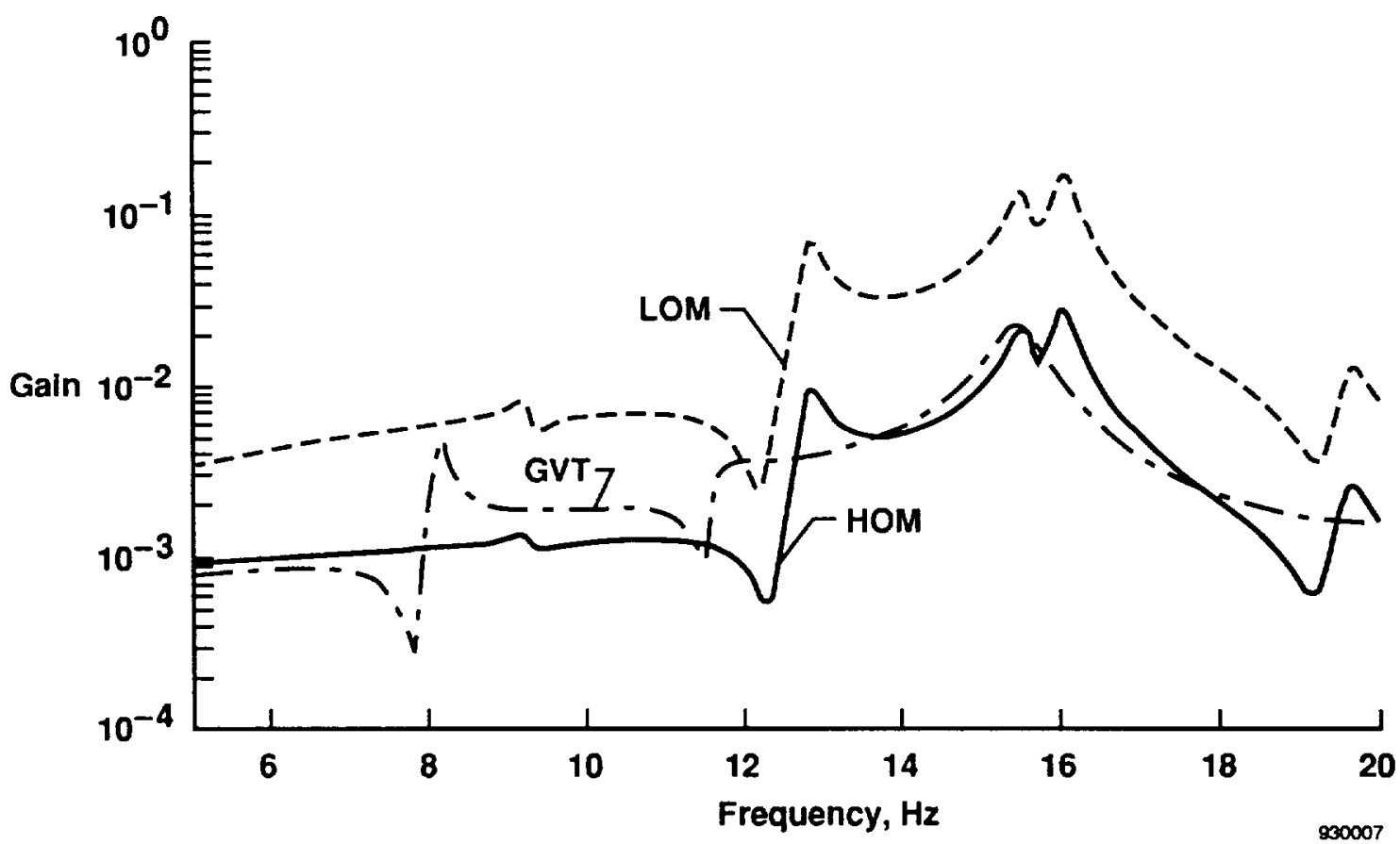

(a) Rudder command to roll rate.

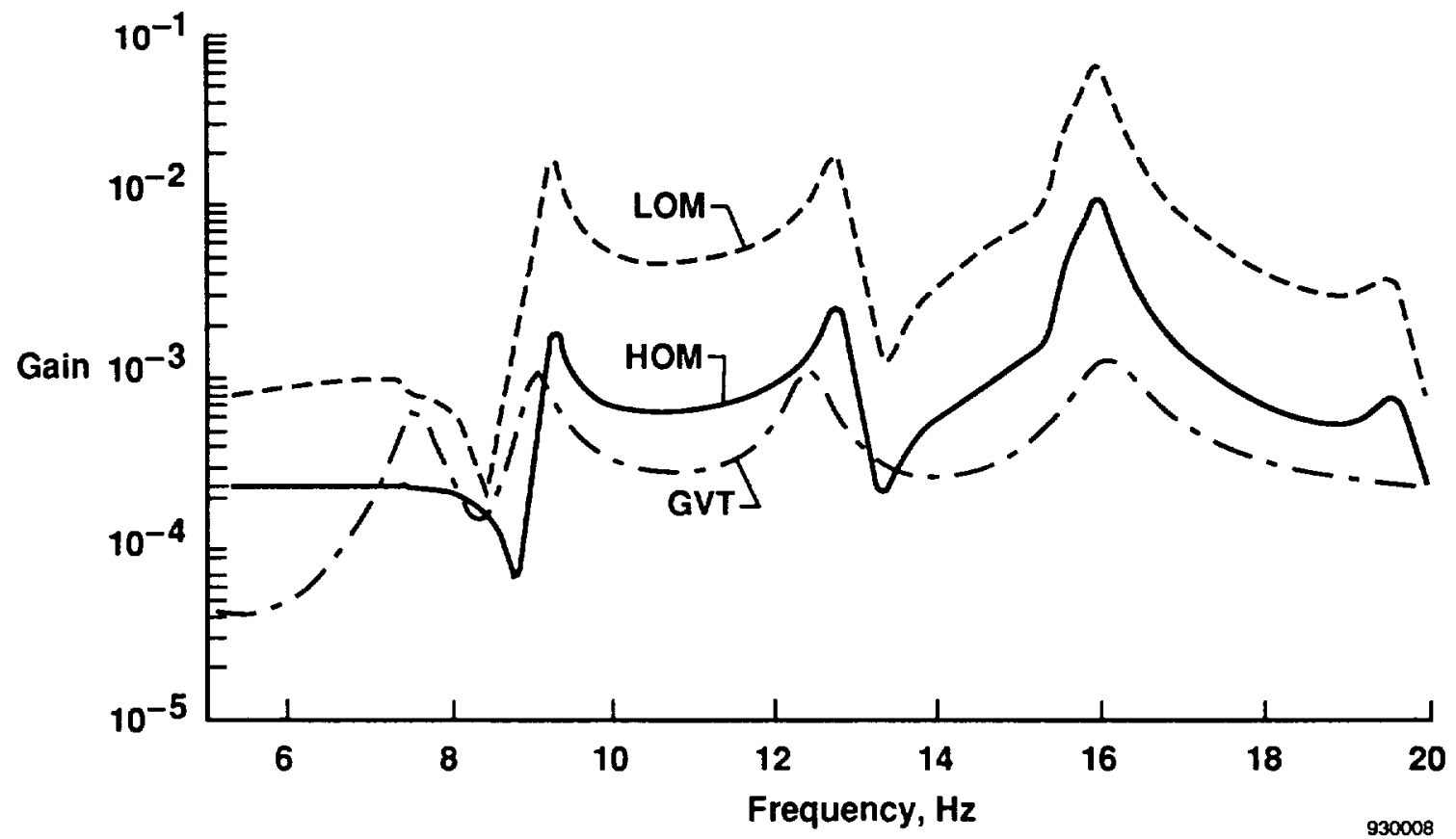

(b) Rudder command to yaw rate.

Fig. 6 Open-loop frequency response comparisons between analytical servoelastic models using high-order model (HOM) and low-order model (LOM) actuators, and ground vibration test (GVT) results. 


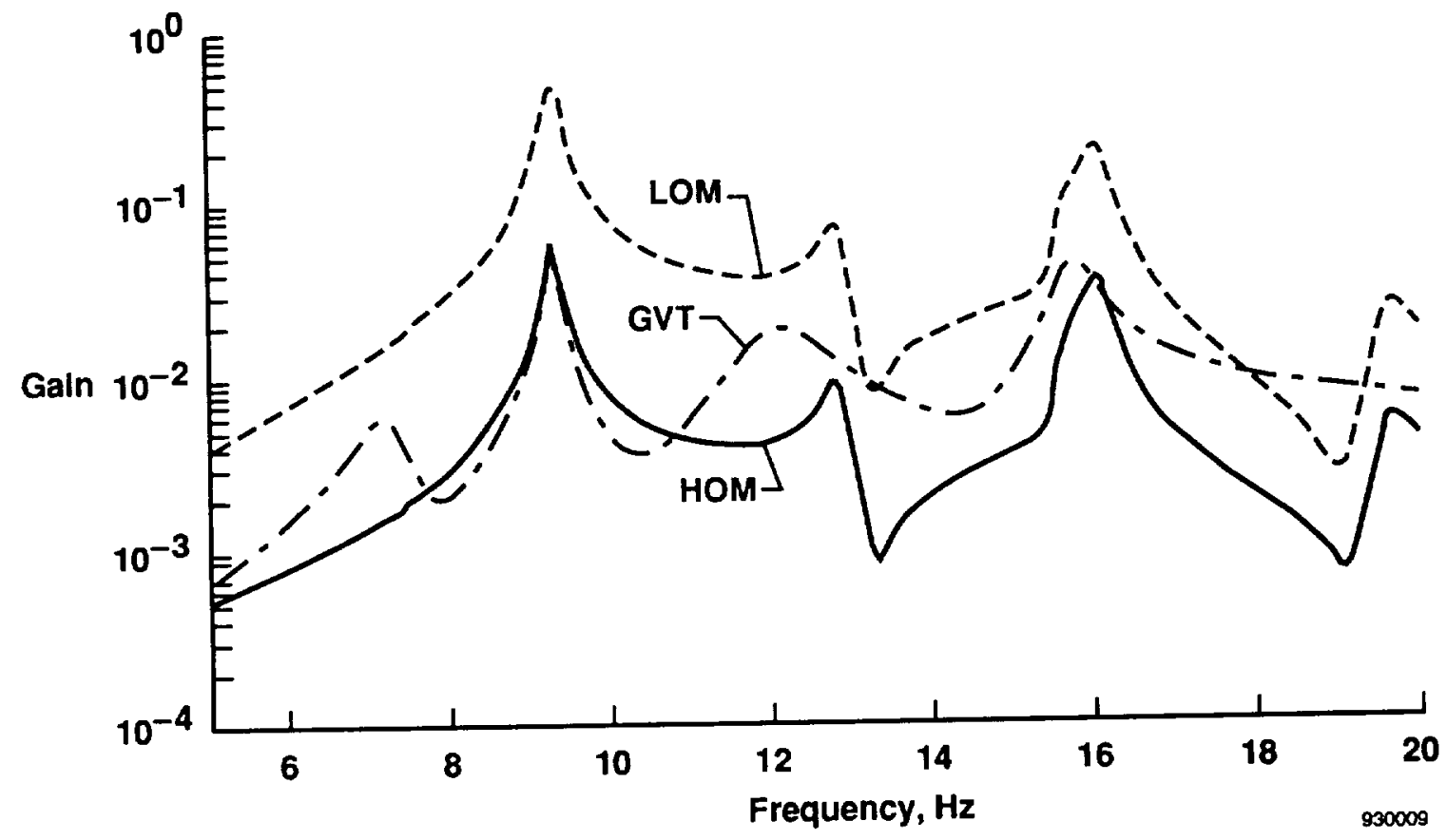

(c) Rudder command to lateral acceleration feedback.

Fig. 6 Concluded. 

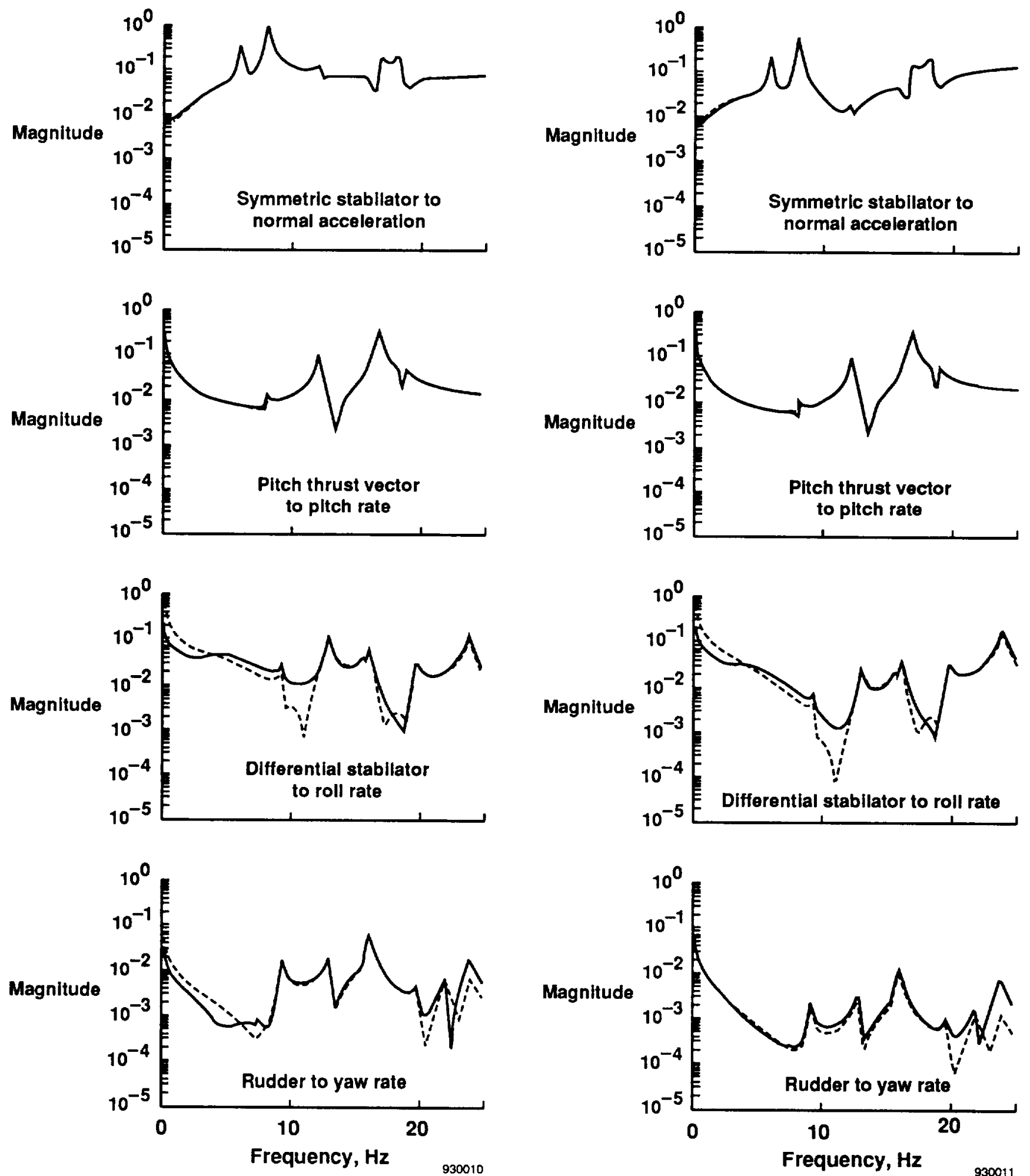

(a) Low-order actuator model.

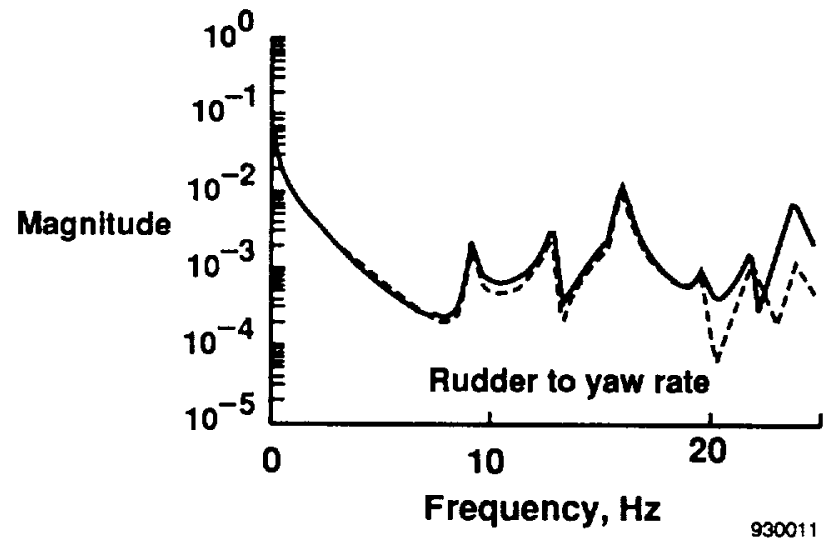

(b) High-order actuator model.

Fig. 7 Open-loop frequency responses of surface commands to sensor feedbacks. Comparisons are between models with zero-order (0aero, dashed line) and fourth-order (4 aero, solid line) aerodynamic models computed for $30,000-\mathrm{ft}$ altitude, $30 \mathrm{lb} / \mathrm{ft}^{2}$ dynamic pressure, and $40^{\circ}$ angle of attack. 

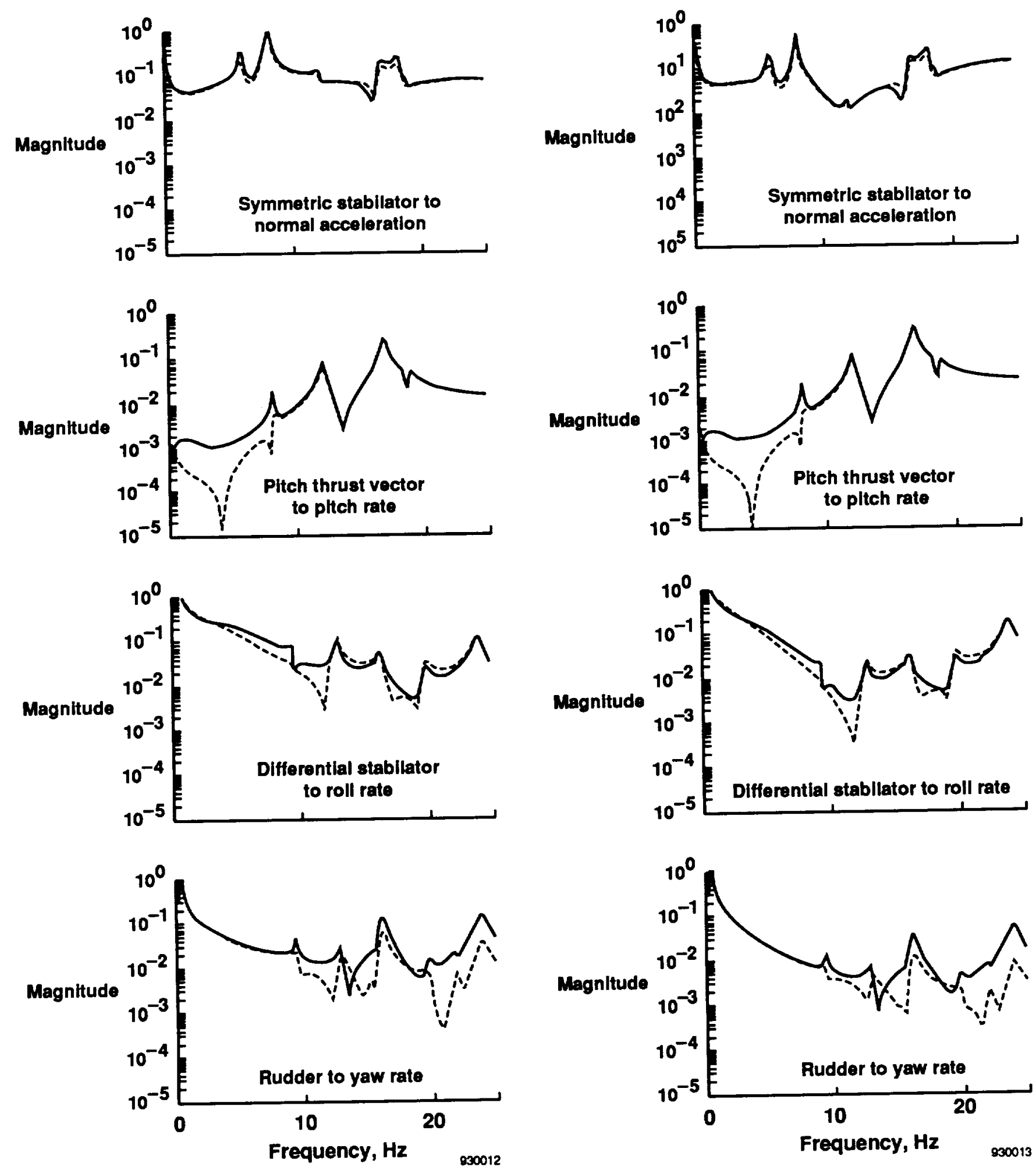

(a) Low-order actuator model.

(b) High-order actuator model.

Fig. 8 Open-loop frequency responses of surface commands to sensor feedbacks. Comparisons are between models with zero-order (0aero, dashed line) and fourth-order (4aero, solid line) aerodynamic models computed for $30,000-\mathrm{ft}$ altitude, $170 \mathrm{lb} / \mathrm{ft}^{2}$ dynamic pressure, and $5^{\circ}$ angle of attack. 

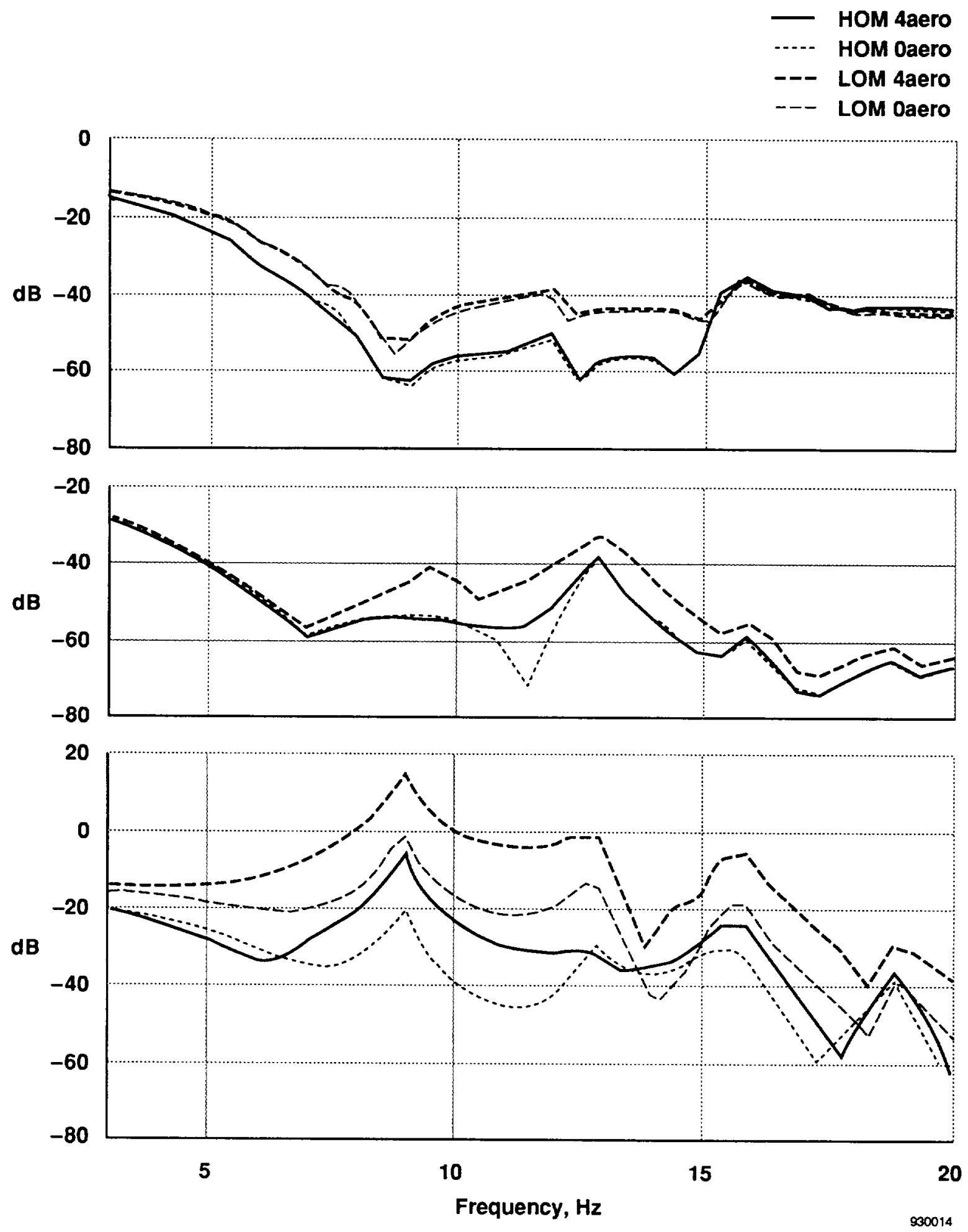

(a) 30,000-ft altitude, $170 \mathrm{lb} / \mathrm{ft}^{2}$ dynamic pressure, and $5^{\circ}$ angle of attack.

Fig. 9 F/A-18 RFCS TVCS loop gains from longitudinal (top), lateral (middle), and directional (bottom) loops using models with variations in actuator and aerodynamic modeling. 


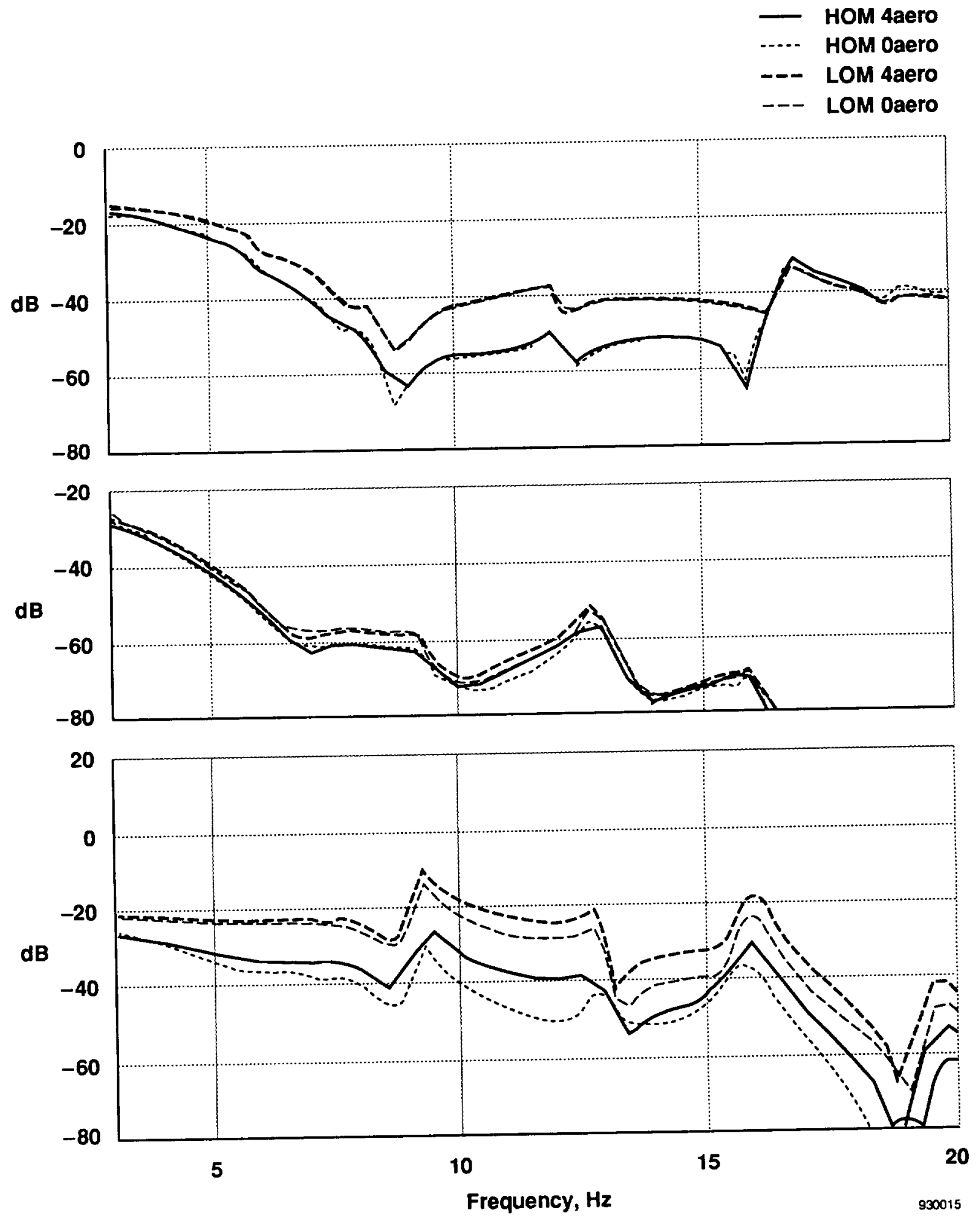

(b) 30,000-ft altitude, $100 \mathrm{lb} / \mathrm{ft}^{2}$ dynamic pressure, and $10^{\circ}$ angle of attack.

Fig. 9 Continued. 

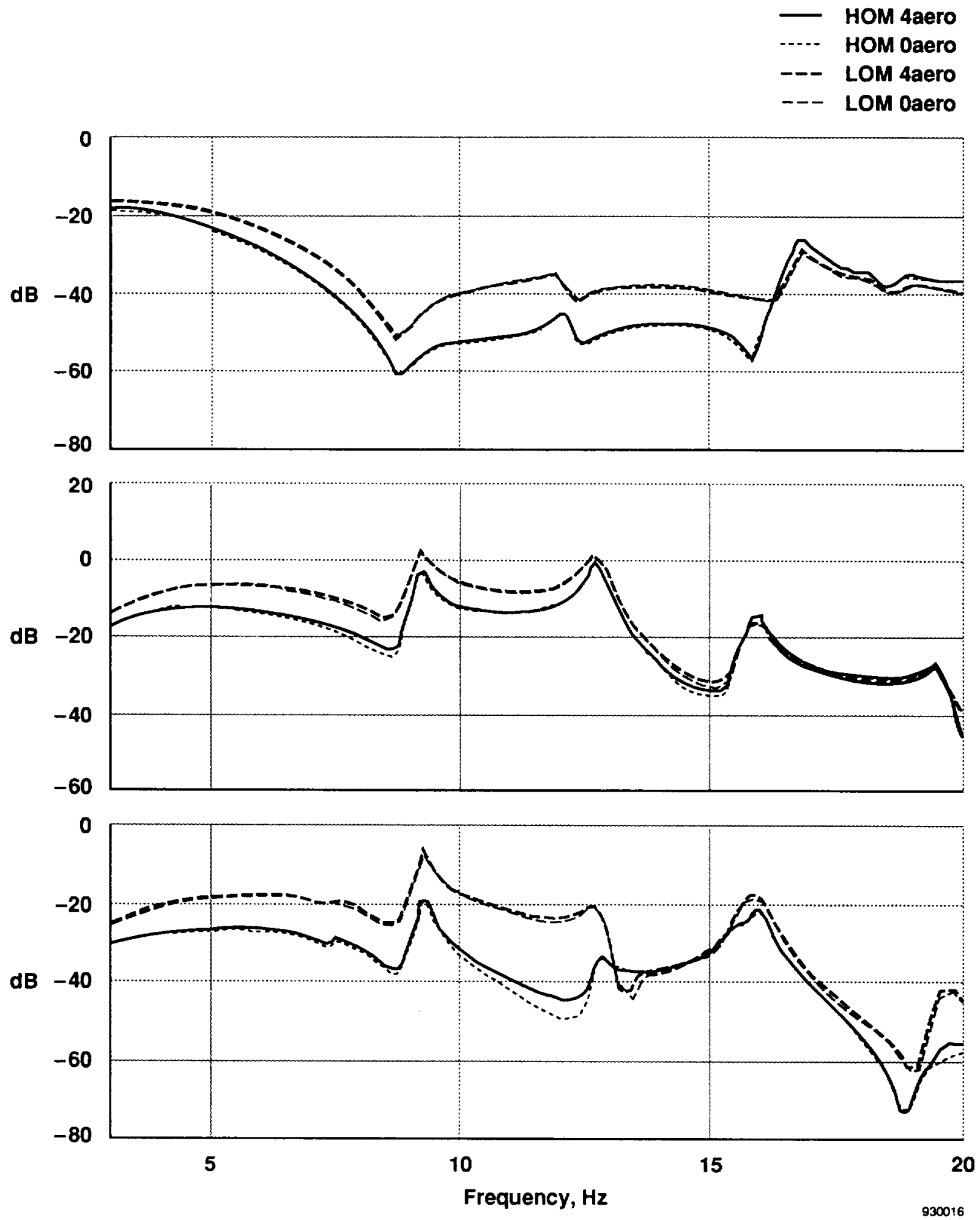

(c) 30,000 - $\mathrm{ft}$ altitude, $30 \mathrm{lb} / \mathrm{ft}^{2}$ dynamic pressure, and $40^{\circ}$ angle of attack.

Fig. 9 Continued. 

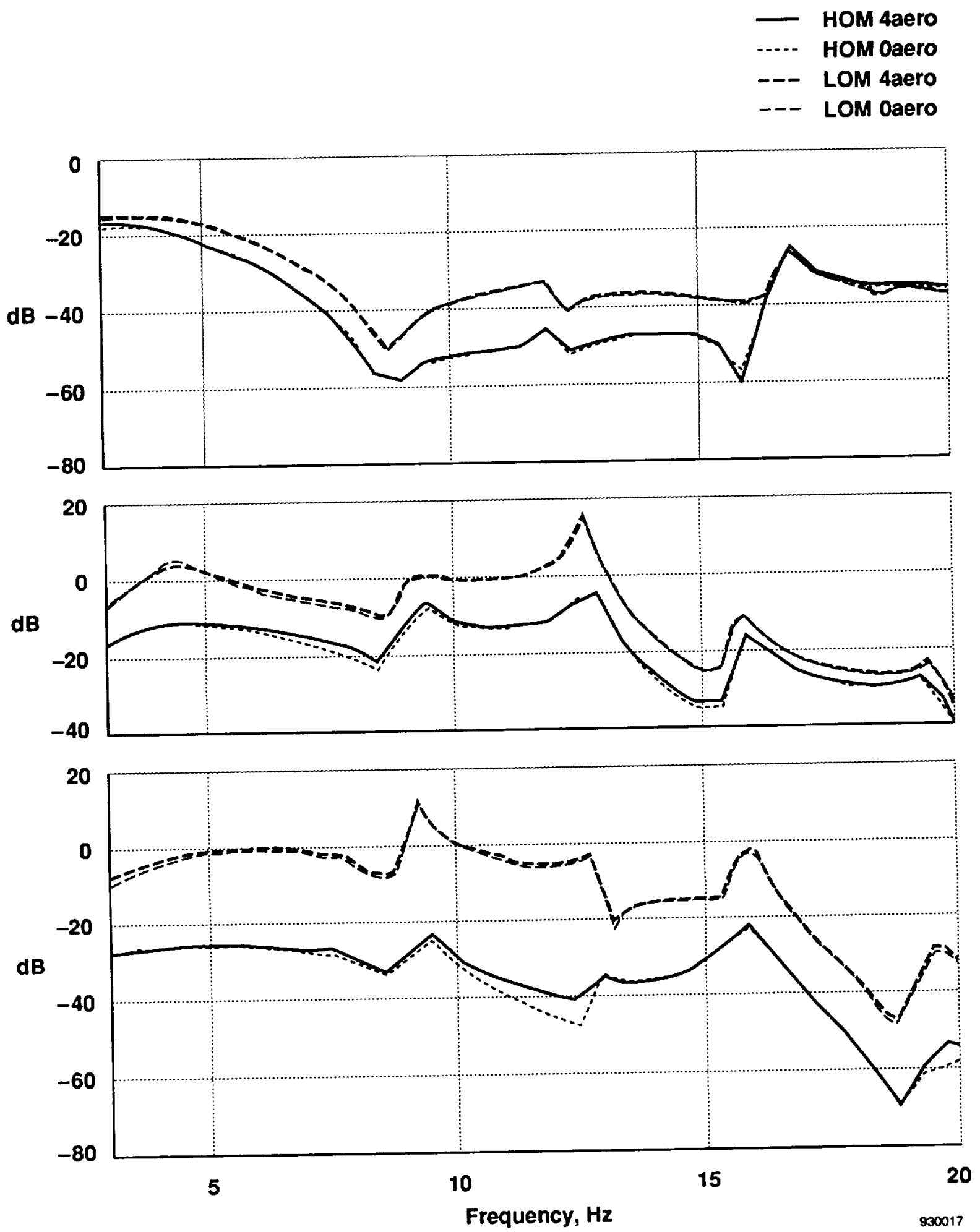

(d) 30,000-ft altitude, $30 \mathrm{lb} / \mathrm{ft}^{2}$ dynamic pressure, and $70^{\circ}$ angle of attack.

Fig. 9 Concluded. 


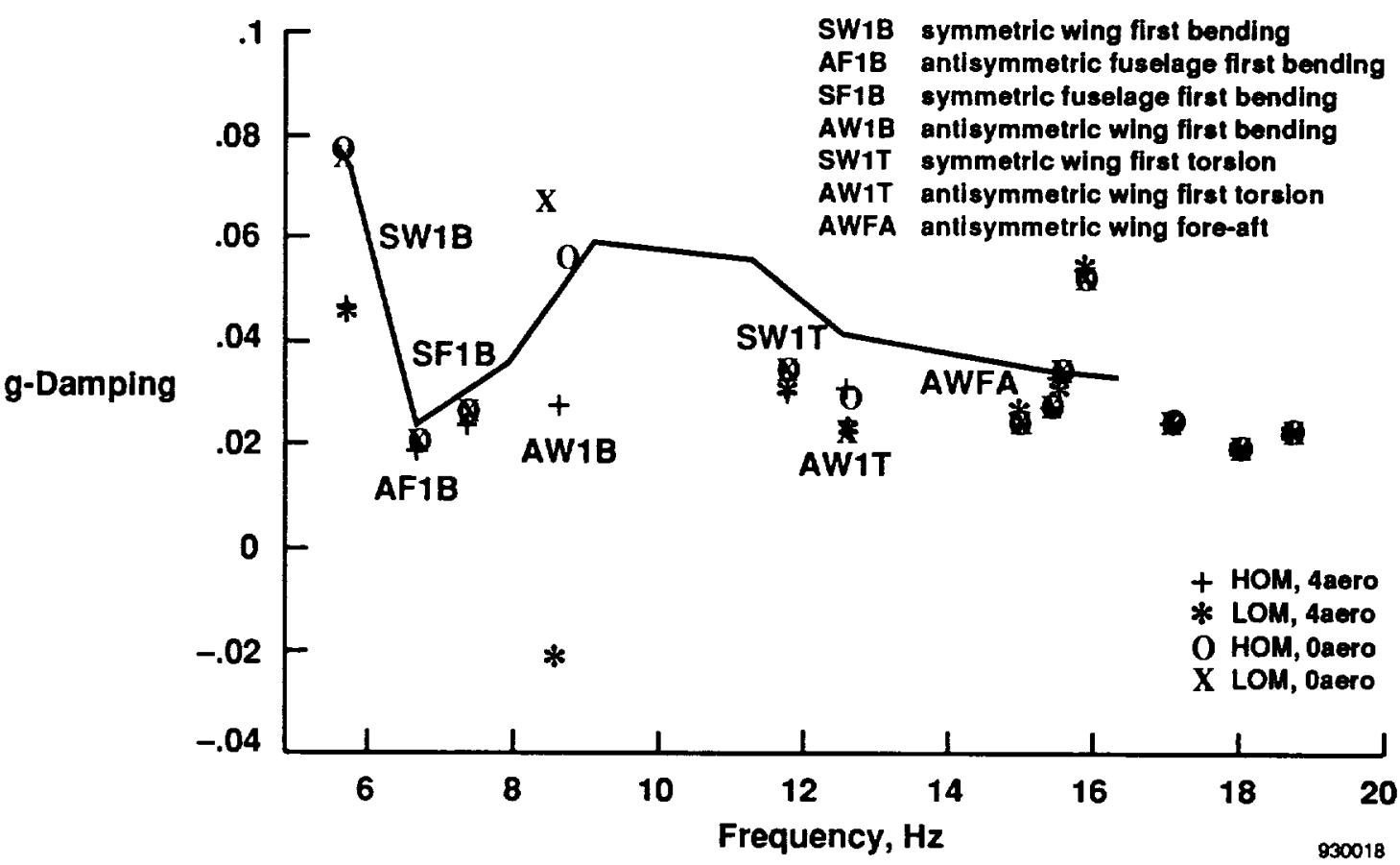

(a) $5^{\circ}$ angle of attack.

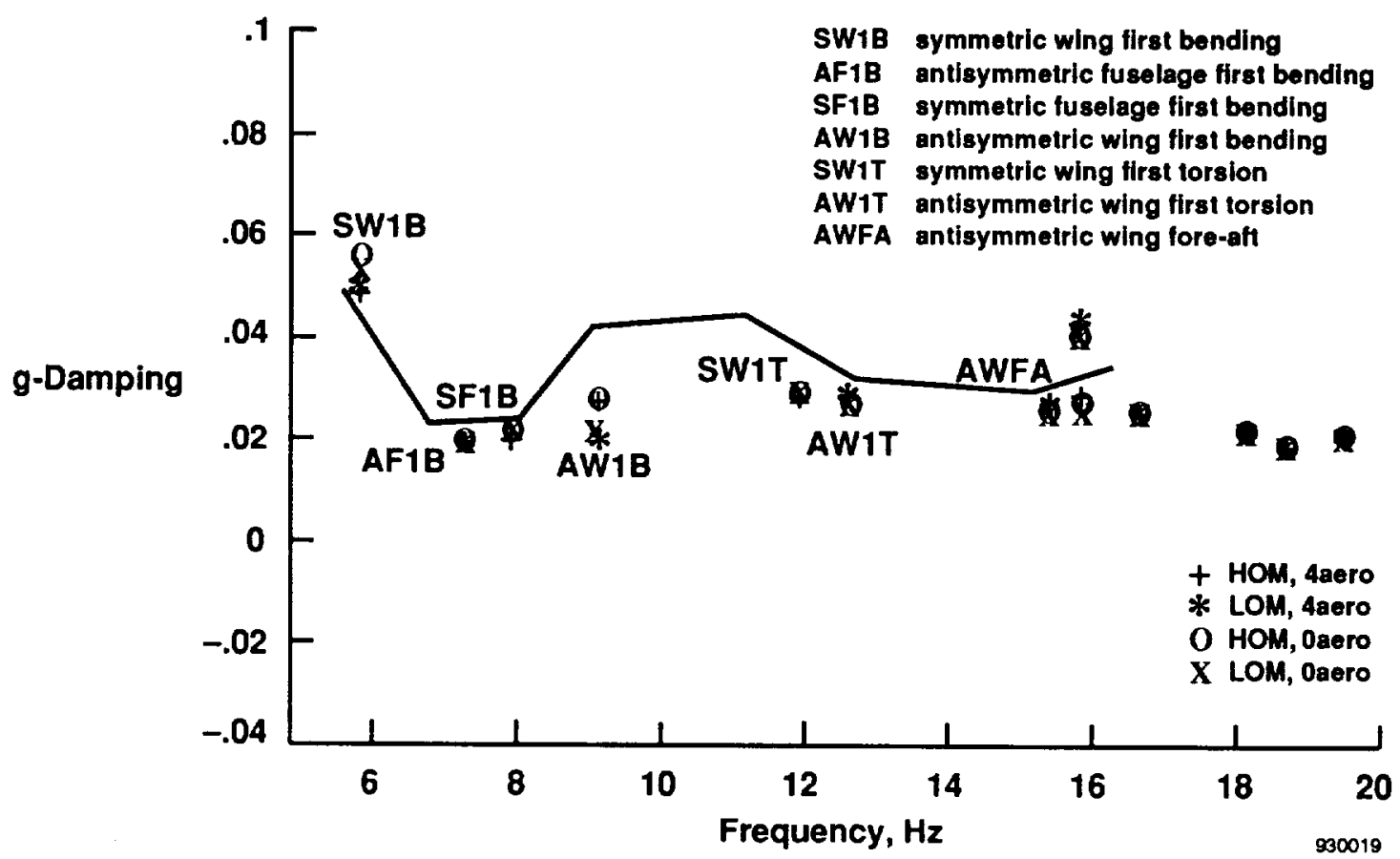

(b) $10^{\circ}$ angle of attack.

Fig. 10 Predicted structural mode damping compared to flight data estimation results (solid line), as a function of angle of attack, for the primary modes of interest with variations in actuator and aerodynamic modeling. 


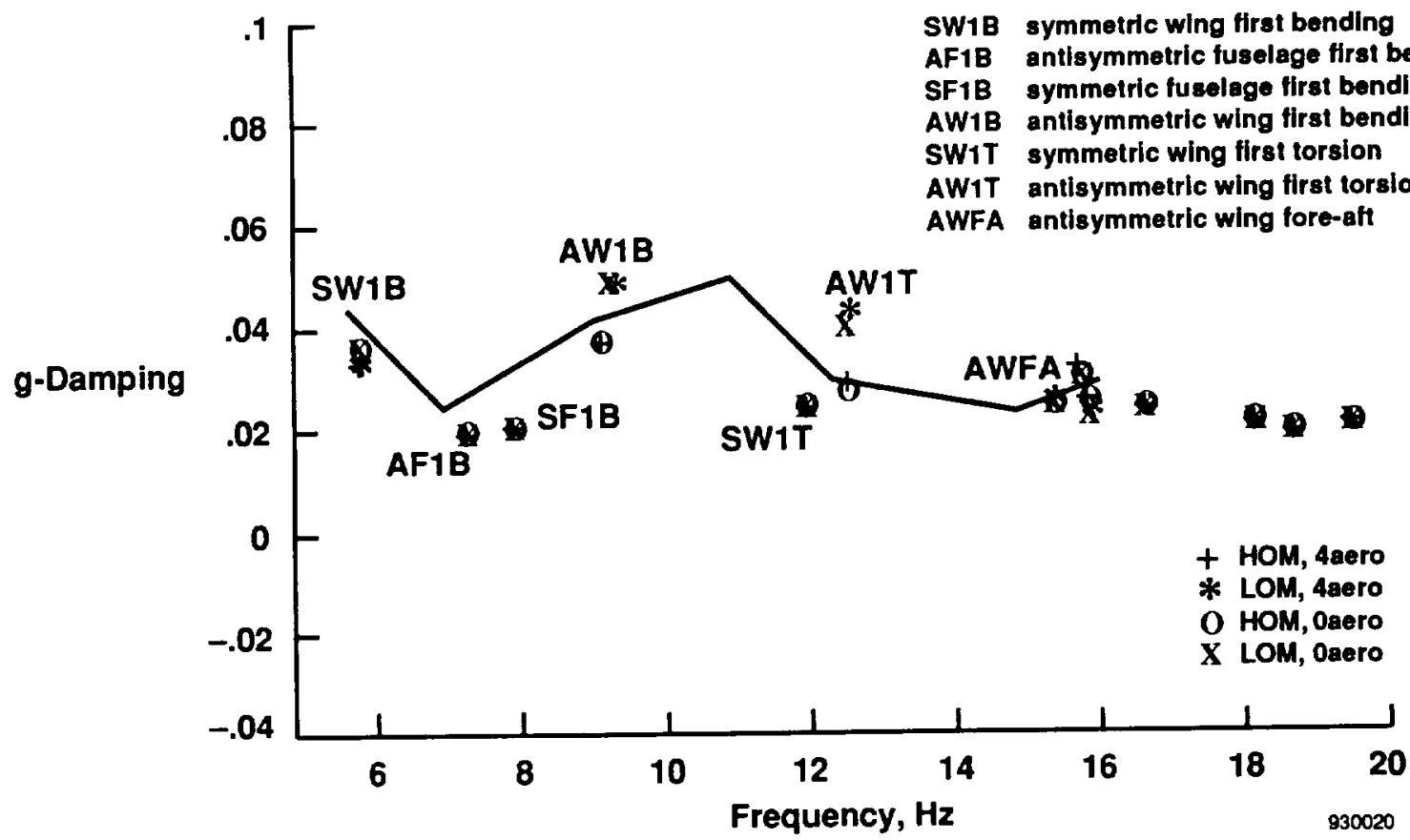

(c) $40^{\circ}$ angle of attack.

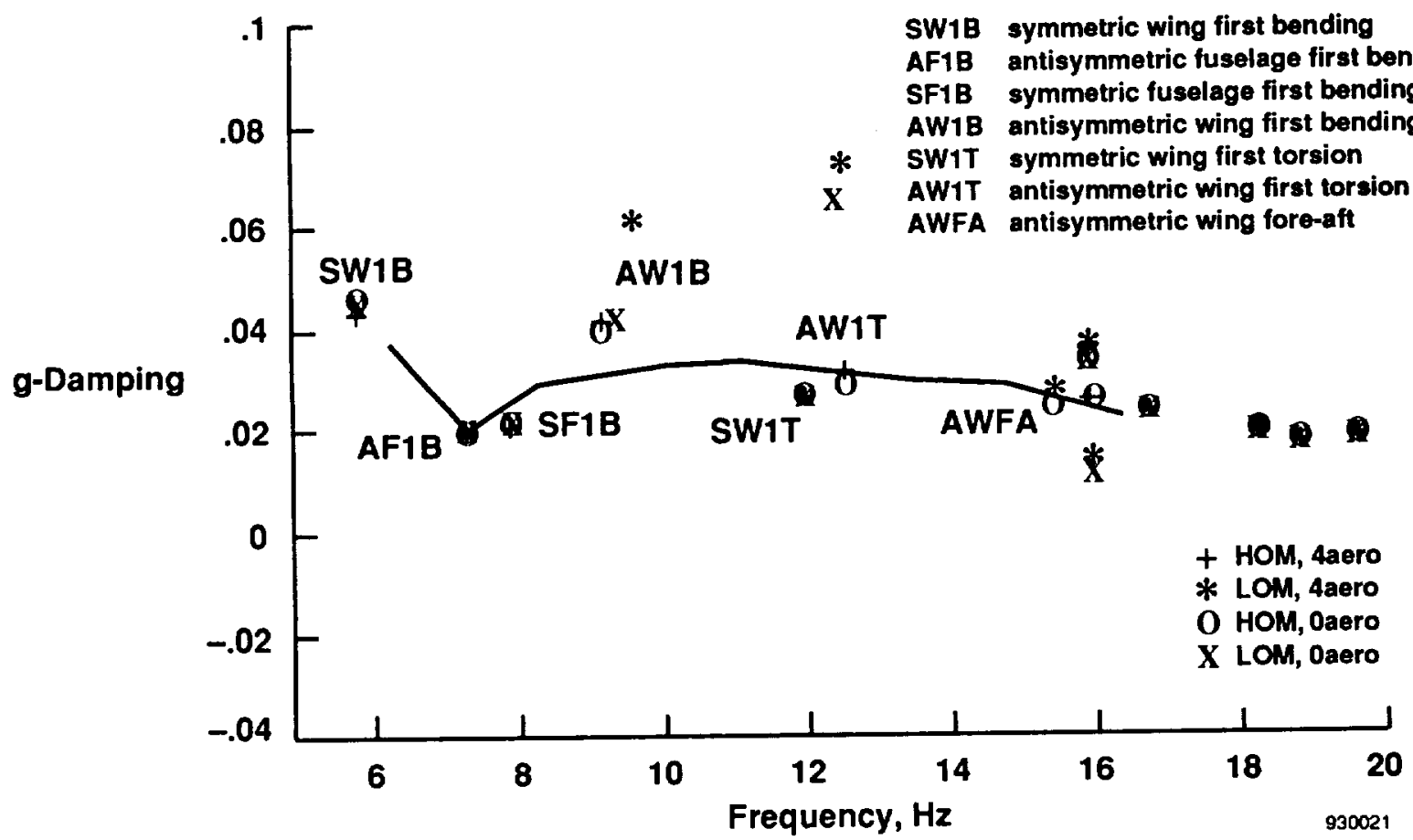

(d) $70^{\circ}$ angle of attack.

Fig. 10 Concluded. 


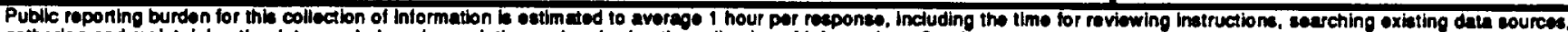
gathering and maintaining the data meded, and completing and reviewing the collection of lnformation. Sond comments renarding this burdon estimete or amy other eapect of thi

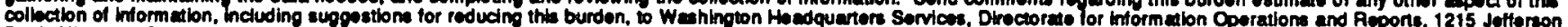
Devis Highway, Sulte 1204. Arlington, VA 22202-4302, and to the Oflice of Managemem and Budget, Peponwork Roduction Project (0704-0188). Waehington, DC 20503.

\begin{tabular}{|l|l|l}
\hline 1. AGENCY USE ONLY (Leavo blenk) & $\begin{array}{l}\text { 2. REPORT DATE } \\
\text { June } 1993\end{array}$ & $\begin{array}{l}\text { 3. REPORT TYPE AND DATES COVERED } \\
\text { Technical Memorandum }\end{array}$ \\
\hline
\end{tabular}

4. TITLE AND SUBTITLE

Actuator and Aerodynamic Modeling for High-Angle-of-Attack Aeroservoelasticity

6. AUTHOR(S)

Martin J. Brenner

7. PERForming ORganization NAME(S) AND ADDRESS(ES)

NASA Dryden Flight Research Facility

P.O. Box 273

Edwards, Califomia 93523-0273

9. SPONSORING/MONITORING AOENCY NAME(S) AND ADDRESS(ES)

National Aeronautics and Space Administration

Washington, DC 20546-0001
WU 533-02-35

8. PERFORMING ORGANIZATION REPORT NUMBER

H-1904

\section{SUPPLEMENTARY NOTES}

Prepared as ALAA-93-1419 for presentation at the AIAA/ASME/ASCE/AHS/ASC Structures, Structural Dynamics and Materials Conference, AIAAJASME Adaptive Structures Fonum, LaJolla, Califomia, April 19-22, 1993.

12a. DISTAIBUTION/AVAILABILITY STATEMENT

12b. DISTRIBUTION CODE

Unclassified - Unlimited

Subject Category 08

13. ABSTRACT (Maximum 200 words)

Accurate prediction of airframe/actuation coupling is required by the imposing demands of modem flight control systems. In particular, for agility enhancement at high angle of attack and low dynamic pressure, structural integration characteristics such as hinge moments, effective actuator stiffness, and airframe/control surface damping can have a significant effect on stability predictions. Actuator responses are customarily represented with low-order transfer functions matched to actuator test data, and control surface stiffness is often modeled as a linear spring. The inclusion of the physical properties of actuation and its installation on the airframe is therefore addressed in this paper using detailed actuator models which consider the physical, electrical, and mechanical elements of actuation. The aeroservoelastic analysis procedure is described in which the actuators are modeled as detailed high-order transfer functions and as approximate low-order transfer functions. The impacts of unsteady aerodynamic modeling on aeroservoelastic stability are also investigated in this paper by varying the order of approximation, or number of aerodynamic lag states, in the analysis. Test data from a thrustvectoring configuration of an F/A-18 aircraft are compared to predictions to determine the effects on accuracy as a function of modeling complexity.

14. SUBJECT TERMS

Actuator dynamics; Aeroservoelasticity; High angle of attack; Modal stability; Structural dynamics; Unsteady aerodynamics

15. NUMBER OF PAGES 30

16. PAICE CODE A03

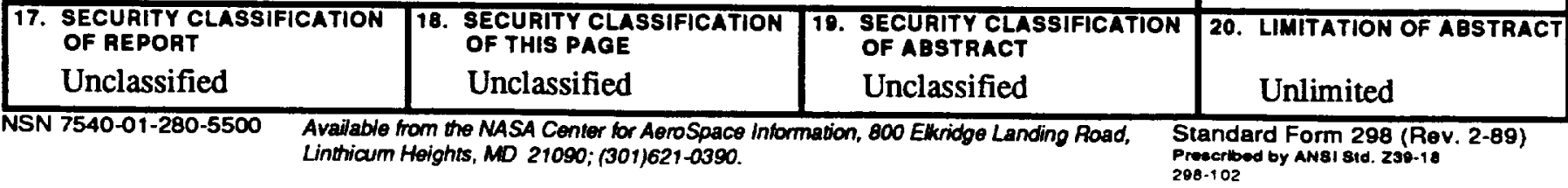

